NBER WORKING PAPER SERIES

\title{
HOURS, OCCUPATIONS, AND GENDER DIFFERENCES \\ IN LABOR MARKET OUTCOMES
}

\author{
Andrés Erosa \\ Luisa Fuster \\ Gueorgui Kambourov \\ Richard Rogerson \\ Working Paper 23636 \\ http://www.nber.org/papers/w23636
NATIONAL BUREAU OF ECONOMIC RESEARCH
1050 Massachusetts Avenue
Cambridge, MA 02138
July 2017

We thank Fabien Postel-Vinay and Henry Siu as well as seminar participants at the Barcelona Summer School in Economics, Canadian Economics Association Meeting, Canadian Macro Study Group, Cornell, Edinburgh MacCaLM Workshop, Federal Reserve Bank of Chicago, Federal Reserve Bank of Philadelphia, Guelph Workshop on Skills and Human Capital, IFS Conference on Labor Supply and the Welfare State, Oslo, Sichuan, Society for Economic Dynamics, Stockholm School of Economics, Sveriges Riksbank, Stanford, Toronto, and UCLA. Erosa and Fuster acknowledge financial support from the Spanish Economics Minister grant \#ECO2015-68615-P. Kambourov acknowledges financial support from SSHRC Grant \#435-2014-0815. The views expressed herein are those of the authors and do not necessarily reflect the views of the National Bureau of Economic Research.

At least one co-author has disclosed a financial relationship of potential relevance for this research. Further information is available online at http://www.nber.org/papers/w23636.ack

NBER working papers are circulated for discussion and comment purposes. They have not been peer-reviewed or been subject to the review by the NBER Board of Directors that accompanies official NBER publications.

(C) 2017 by Andrés Erosa, Luisa Fuster, Gueorgui Kambourov, and Richard Rogerson. All rights reserved. Short sections of text, not to exceed two paragraphs, may be quoted without explicit permission provided that full credit, including $\odot$ notice, is given to the source. 
Hours, Occupations, and Gender Differences in Labor Market Outcomes

Andrés Erosa, Luisa Fuster, Gueorgui Kambourov, and Richard Rogerson

NBER Working Paper No. 23636

July 2017

JEL No. E2,J2

\begin{abstract}
$\underline{\text { ABSTRACT }}$
We document a robust negative relationship between the log of mean annual hours in an occupation and the standard deviation of log annual hours within that occupation. We develop a unified model of occupational choice and labor supply that features heterogeneity across occupations in the return to working additional hours and show that it can match the key features of the data both qualitatively and quantitatively. We use the model to shed light on gender differences in labor market outcomes that arise because of gender asymmetries in home production responsibilities. Our model generates large gender gaps in hours of work, occupational choices, and wages. In particular, an exogenous difference in time devoted to home production of ten hours per week increases the observed gender wage gap by roughly eleven percentage points and decreases the share of females in high hours occupations by fourteen percentage points. The implied misallocation of talent across occupations has significant aggregate effects on productivity and welfare.
\end{abstract}

\author{
Andrés Erosa \\ Universidad Carlos III de Madrid \\ Department of Economics \\ Calle Madrid 126, 28903 \\ Getafe, Madrid \\ Spain \\ aerosa@eco.uc3m.es \\ Luisa Fuster \\ Universidad Carlos III de Madrid \\ Department of Economics \\ Calle Madrid 126, 28903 \\ Getafe, Madrid \\ Spain \\ lfuster@eco.uc3m.es
}

\author{
Gueorgui Kambourov \\ Department of Economics \\ University of Toronto \\ 150 St. George Street \\ Toronto, ON M5S 3G7 \\ CANADA \\ g.kambourov@utoronto.ca \\ Richard Rogerson \\ Woodrow Wilson School of \\ Public and International Affairs \\ 323 Bendheim Hall \\ Princeton University \\ Princeton, NJ 08544 \\ and NBER \\ rdr@princeton.edu
}




\section{Introduction}

Two classic topics in labor supply are time allocation and occupational choice. Interestingly, textbook treatments of time allocation abstract from occupational choice, and textbook treatments of occupational choice typically take the time allocated to market work as given. The first objective of this paper is to argue that there are important interactions between time allocation and occupational choice, and develop a model to account for these interactions.

Figure 1 provides a scatter plot of the mean and standard deviation of log individual annual hours worked by occupation and serves to motivate our first objective. A strong pattern emerges, indicating a negative relationship between the log of mean annual hours in an occupation and the standard deviation of log annual hours in that occupation. This pattern is robust over time and across age, education, and gender groups and is observed both at the intensive (weekly hours) and extensive (number of weeks) margins.

Figure 1: The Log of Mean Annual Hours vs. the Standard Deviation of Log Annual Hours, CPS 1976-2010: by 3-Digit Occupations.

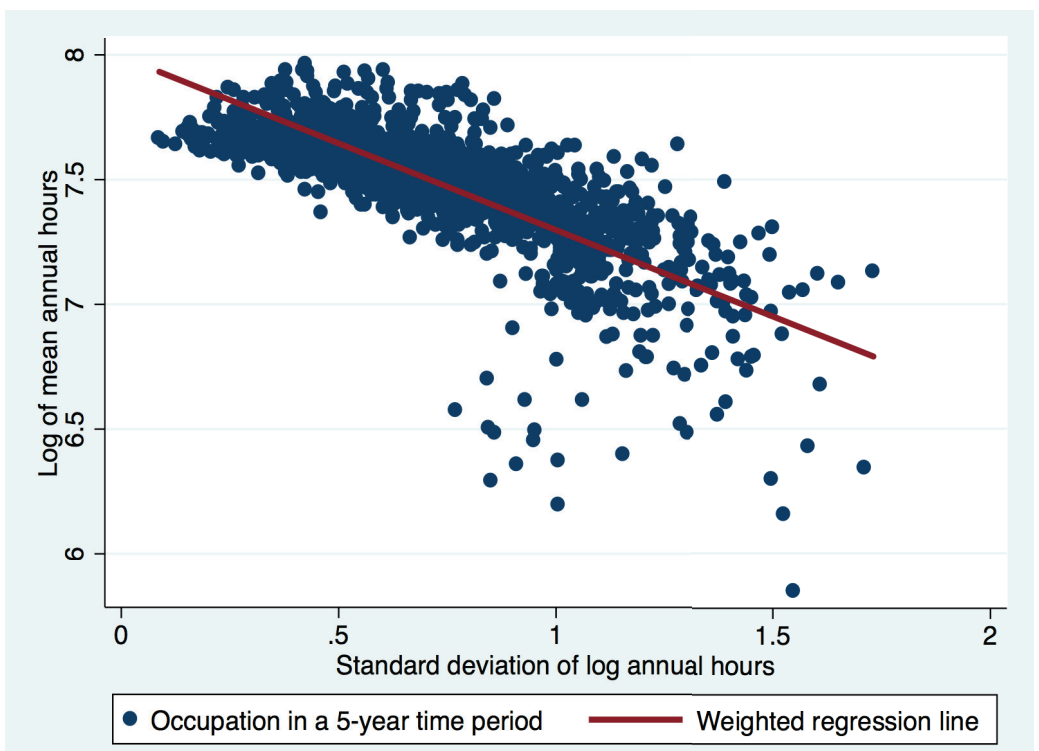

Notes: Each point represents a 3-digit occupation in a given 5-year time period. The scatter plot describes the relationship between the log of mean annual hours worked and the standard deviation of log annual hours in a given occupation in a specific 5-year time period.

The differences in labor supply across occupations depicted in this figure are large. For example, an average occupation in the top-left part of the figure has log mean hours of around 7.7 and a standard deviation of log hours of 0.4 , whereas occupations in the middle of the figure have log mean hours of 7.4, with a standard deviation of log hours at around 0.8. This difference in mean hours across occupations is similar to the large aggregate differences observed across countries. We believe that understanding these differences in hours worked across occupations could prove important for understanding the behavior of aggregate labor supply in many contexts: over time, both secularly and over the business cycle, across 
countries, and across demographic groups within an economy at a point in time. Each of these contexts is associated with differences or changes in the occupational distribution, and as a result may impact aggregate hours. ${ }^{1}$

In this paper we integrate time allocation decisions into an otherwise standard model of occupational choice. Building on the earlier work of Cogan (1981) and the more recent work of French (2005) and Prescott, Rogerson and Wallenius (2009), we assume a non-convexity in the mapping from individual hours worked to the supply of efficiency units of labor. A key innovation is that we assume the extent of this non-convexity differs across occupations. This assumption is consistent with a variety of empirical studies that find differential returns on wages across occupations from an additional hour of work. ${ }^{2}$ Our model generates an intimate connection between occupational choice and time allocation: holding all else constant, a decrease in the desired hours of work by an individual will bias their occupational choice to an occupation in which the non-convexity is not as severe. This element will play a key role in our subsequent quantitative analysis. We establish that our simple benchmark model can generate the pattern in Figure 1 both qualitatively and quantitatively.

Having developed a simple prototype model of time allocation and occupational choice, the second objective of the paper is to use the model to isolate and measure some key forces associated with gender differences in labor market outcomes. Recent work by Bertrand, Goldin and Katz (2010), Goldin (2014), and Cortés and Pan (2017b) highlights the connection between gender differences in hours of work, occupational choice, and wages. Extending our prototype model to include households consisting of a male and female member, our model provides a structure that can usefully address these connections. ${ }^{3}$

We use our model to quantitatively evaluate the importance of one particular source of gender differences in labor market outcomes. Motivated by the discussion in Goldin (2014), we assume an exogenous gender difference in time allocated to non-market activities associated with home production, and assess the extent to which this gender asymmetry in non-market outcomes is propagated to gender asymmetries in market outcomes, in particular occupational choice and the gender wage gap. ${ }^{4}$ Intuitively, our model captures the following responses. Because women do more non-market work they have less time available for market work. Conditional on working in an occupation that rewards long hours, they will receive lower rewards. It also discourages some women from entering such occupations, thereby leading to selection effects. These direct effects on women's choices then feed into joint household choices, further amplifying them.

We calibrate a version of our model to capture the salient features of hours worked and occupational choice by gender and quantitatively assess the overall effect of gender asymmetries in non-market work on labor market outcomes. Our main results are as follows.

\footnotetext{
${ }^{1}$ Acemoglu and Autor (2011) and Autor and Dorn (2013) analyze the effect of changes in the occupational structure over time on employment and wages. Kambourov and Manovskii (2009a) emphasize the effect of increased occupational mobility on wage inequality while Duernecker and Herrendorf (2016) study the role of the occupational composition in structural transformation.

${ }^{2}$ We discuss this literature in detail later on in the paper.

${ }^{3}$ Our analysis focuses on evaluating a single source of gender differences and a single source of differences between occupations, and so is intended to be complementary to studies that focus on other differences. See Cortés and Pan (2017a) for an overview of these complementary explanations.

${ }^{4}$ There is of course a large literature documenting various features of the gender wage gap. See, for example the recent survey by Blau and Kahn (2016), as well as their earlier survey Blau and Kahn (2000).
} 
First, we find that an exogenous difference in time devoted to home production has a large effect on occupational choice, reducing the share of females in high hours worked occupations by fourteen percentage points relative to males. Second, this asymmetry in home production time generates a gender wage gap of roughly eleven percentage points taking as given any difference due to exogenous productivity differences or gender wage discrimination. Third, our analysis attributes an important role to all three components highlighted in our discussion of the qualitative responses in the gender wage gap: the endogenous gender wage gap in our model reflects both the direct effect of lower hours on wages, a change in occupational structure, and a selection effect. Significantly, our model generates a gender wage gap even in the occupation that features no reward for longer hours. Fourth, we find that household interactions serve to significantly amplify the effect of these changes.

A recent paper by Hsieh, Hurst, Jones and Klenow (2016) argues that the US economy has had a significant degree of misallocation of talent across occupations along the dimensions of race and gender, and that this misallocation has quantitatively important effects on aggregate output. Their analysis was silent on the issue of what underlying factors were driving the observed misallocation. Our analysis has studied one particular driving force: the uneven division of nonmarket responsibilities. With this in mind we also ask how aggregate productivity and welfare in our model would be enhanced if non-market duties were allocated in a gender neutral way. We find that welfare increases by $6.9 \%$ in terms of consumption equivalents, and that output per hour increases by $5.4 \%$. Obviously, the non-convex occupation is crucial for the large impact of gender equality on welfare and labor productivity. When the non-convex occupation is shut down in the baseline economy, the mean welfare gain from gender equalization drops from $6.9 \%$ to $3.5 \%$. Moreover, the increase in output per hour decreases by more than half from $5.4 \%$ in the baseline economy to $2.2 \%$.

Our paper builds on some basic insights from human capital theory. The theories developed by Becker (1967) and Ben-Porath (1967) stress the importance of modelling human capital and labor supply decisions jointly. The idea that women may face different incentives to accumulate human capital than men due to a higher relative value of non-market activities can be traced back to the influential work of Mincer and Polacheck (1974). Gronau (1988) and Weiss and Gronau (1981) are also important early contributions studying how labor market interruptions affect women's investment in human capital. More recently, Erosa, Fuster and Restuccia (2016b) use quantitative theory to assess how much of the gender wage gap over the life cycle is due to the fact that working hours are lower for women than for men. Knowles (2007) and Adda, Dustmann and Stevens (2017) emphasize the importance of heterogeneity in returns to experience across occupations to understand trends in female labor supply and the career costs of children, respectively. Relative to these authors, we abstract from fertility decisions and develop a simple model of lifetime choices to focus on the interplay between the occupations and hours decisions of husbands and wives. A recent literature builds fully structural life-cycle models of the labor supply decisions of married couples to understand time trends in female labor supply, marriage/divorce decisions, and the effects of taxation (see Eckstein, Keane and Lifshitz (2016), Grenwood, Guner, Kocharkov and Santos (2016), Guner, Kaygusuz and Ventura (2012), Heathcote, Storesletten and Violante (2010), Jones, Manuelli and McGrattan (2015), Knowles (2013), Olivetti (2006)). Our analysis is much simpler but focuses on occupational choice and sorting among couples. Key to our analysis is how household interactions propagate gender differences in discretionary time 
(time allocated to non-market activities) by generating gender asymmetries in the sorting of workers across occupations, hours of work, and wages.

An outline of the paper follows. In the next section we present an empirical analysis to more thoroughly document the key fact shown in Figure 1. We present evidence for both the aggregate as well as for males and females separately. We also document the correlation between occupational hours and wage rates. In Section 3 we develop and analyze a simple benchmark model and illustrate its ability to quantitatively account for the salient facts about hours of work and wages across occupations. In Section 4 we present an extended version of the model that explicitly considers males and females that are (exogenously) combined into two member households. In Section 5 we carry out our main quantitative exercise. We use this model to evaluate the extent to which gender asymmetries in home production can lead to gender asymmetries in market outcomes, and in particular in occupational choices and wages, and provide insight into how the various features of the model interact. Section 6 considers the implications of our calibrated model for the misallocation of talent. Section 7 concludes.

\section{Empirical Facts}

This section provides a more thorough analysis of the key pattern presented in Figure 1. Our analysis is based on the IPUMS-CPS files from the 1976-2010 Current Population Survey (CPS). ${ }^{5}$ The CPS has two key advantages from our perspective. First, it is large, allowing us to study the facts about hours within a large number of three-digit occupations and by gender. Second, it covers the 1976-2010 time period, allowing us to study changes over time. An issue from the perspective of analyzing time series patterns is that the occupational classification has changed four times over the period 1976-2010. ${ }^{6}$ We use the occupational classification provided in Autor and Dorn (2013) to construct consistent occupational codes for the 1976-2010 period. $^{7}$

The CPS provides information on number of weeks and usual hours per week, from which we construct a measure of annual hours. Hourly wages are constructed based on the available information on wage and salary income in the calendar year and annual hours worked in that year. Appendix A provides a detailed description of the variables used in the analysis, as well as the sample restrictions imposed throughout. Our benchmark results use the pooled data from 1986-1995. However, in order to assess the extent to which the patterns have changed over time we also construct seven 5-year periods: (1) 1976-1980; (2) 1981-1985; (3) 1986-1990; (4) 1991-1995; (5) 1996-2000; (6) 2001-2005; (7) 2006-2010.

\footnotetext{
${ }^{5}$ The data and a detailed description can be found at http://cps.ipums.org/cps/.

${ }^{6}$ Specifically, the 1970 census classification scheme is used in 1971-1982, the 1980 census classification scheme is used in 1983-1991, the 1990 census classification scheme is used in 1992-2002, and the 2000 census classification scheme is used in 2003-2010.

${ }^{7}$ The consistent occupational classification is listed in Appendix G.
} 


\subsection{Hours Worked by Occupation}

In this subsection we present the key patterns on hours worked by occupation for men and women separately.

\subsubsection{Men}

The left panel in Figure 2 displays the results for men. Each dot on the graph represents an occupation in the 1986-1995 time period. The vertical axis measures the log of mean annual hours worked in an occupation while the horizontal axis measures the standard deviation of log annual hours in that same occupation. The straight line represents a linear regression, weighted by the relative size of each occupation.

Figure 2: The Log of Mean Annual Hours vs. the Standard Deviation of Log Annual Hours, CPS, 1986-1995: by 3-Digit Occupations.
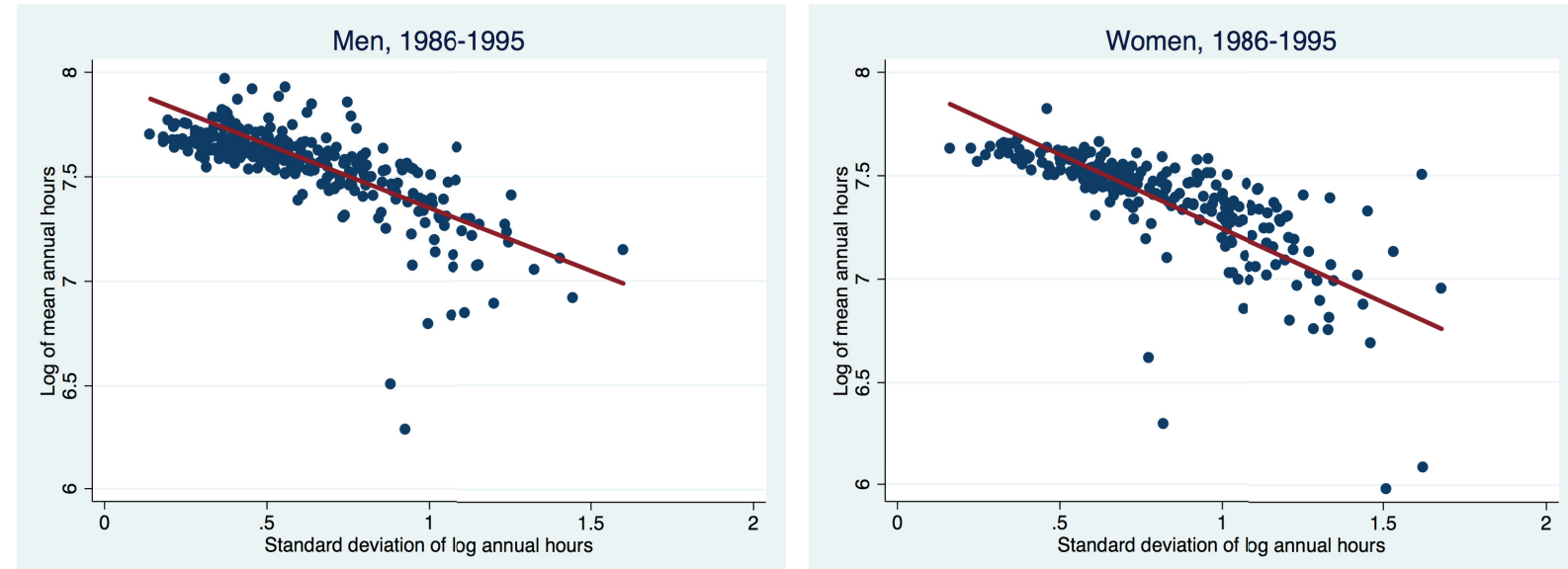

Notes: Each point represents a 3-digit occupation in the 1986-1995 time period. The scatter plot describes the relationship between the log of mean annual hours worked and the variance of log annual hours in a given occupation in the 1986-1995 time period for men and women, respectively.

The graph illustrates a substantial negative relationship between the mean hours worked in an occupation and the dispersion of hours worked in that occupation. ${ }^{8}$

\footnotetext{
${ }^{8}$ As discussed in Appendix B, we see a similar underlying relationship if we look separately at usual hours per week and weeks worked.
} 

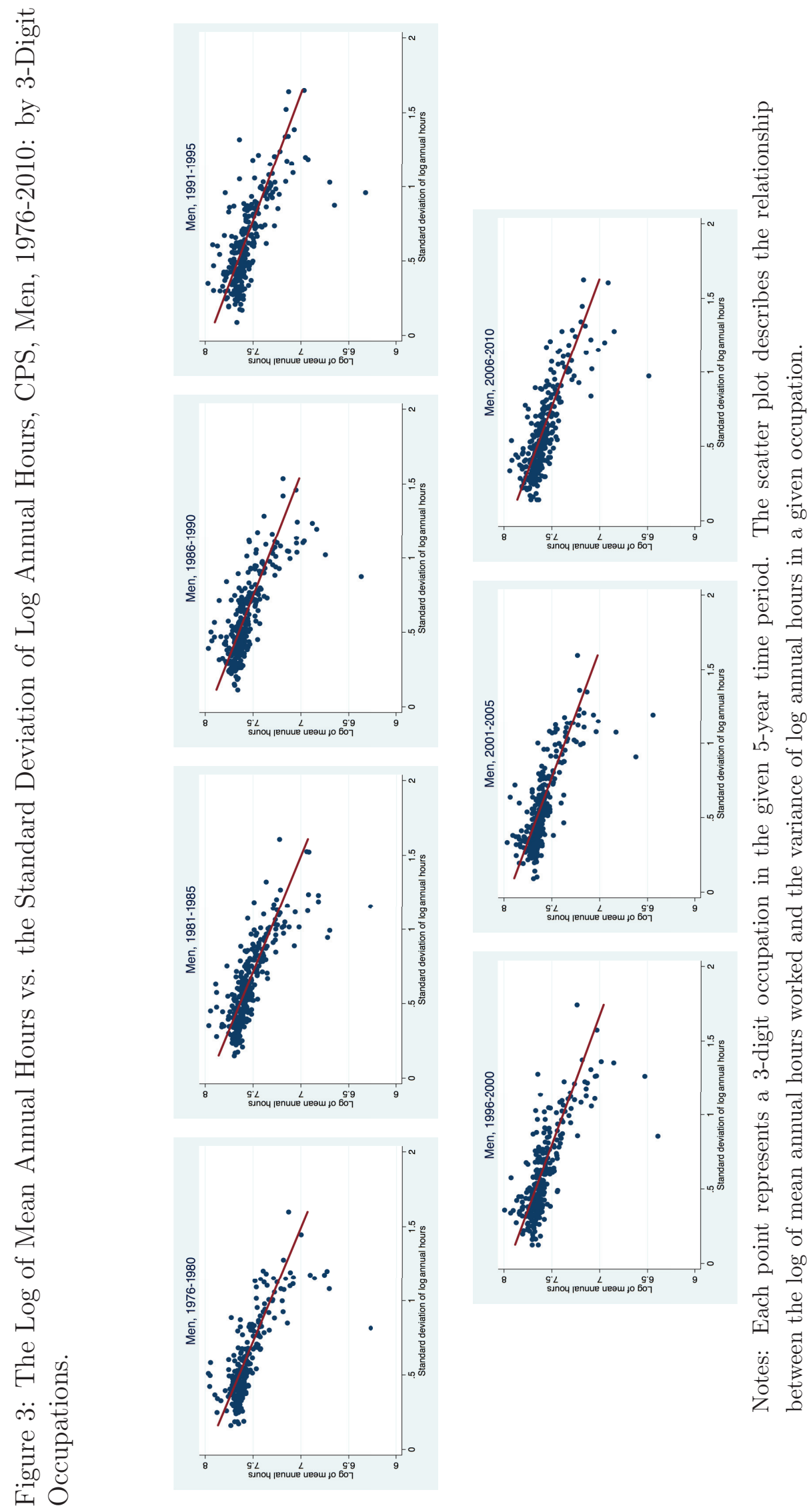

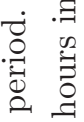

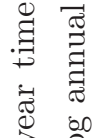
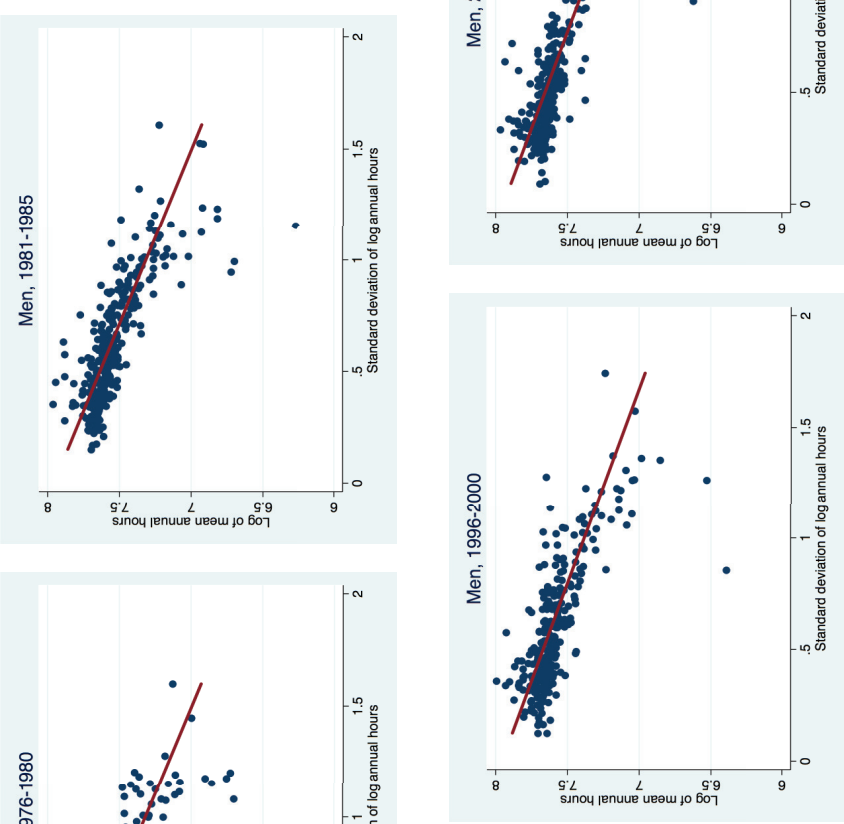

iุ

$\begin{array}{ll}0 & 0 \\ 0 & 0 \\ 00 & 0 \\ 0 & 0\end{array}$

类

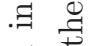

.

苞

$\begin{array}{cc}. & 3 \\ .00 & 0 \\ .7 & \Xi \\ .7 & 0\end{array}$

क อ

莡

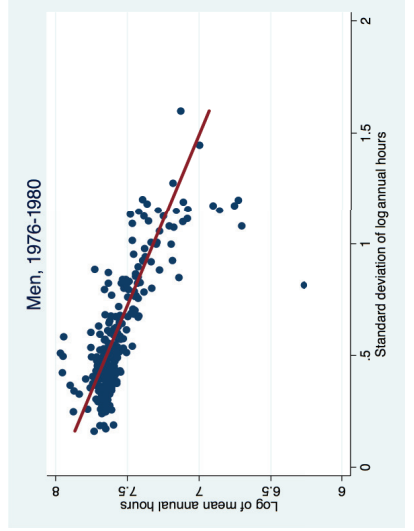

芯

$\begin{array}{cc}\vec{Z} & 4 \\ .7 & 0 \\ 0 & 0 \\ 0 & 0\end{array}$

궝

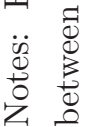


Figure 3 illustrates that this pattern is not special to the time period 1986-1995: we observe the same negative relationship in each of the 5-year periods from 1976 until 2010. An important question for our purposes is whether these differences are relatively constant over time, so that we can think of this as a somewhat fixed characteristic of an occupation. To examine this, Figure 4 shows the log mean annual hours for each occupation in 19911995 and 2006-2010 relative to the initial 1976-1980 time period. Although there are some changes, 30 years later most occupations still line up closely along the 45-degree line. A similar pattern emerges for the changes in the standard deviation of log annual hours, as reported in Figure 5. The plots for the changes in standard deviation over time exhibit more dispersion around the 45 degree line, but this is to be expected if our estimate of the standard deviation of hours within an occupation is noisier than our estimate of mean hours.

Figure 4: Log of Mean Annual Hours, Men, Over Time: by 3-Digit Occupations.
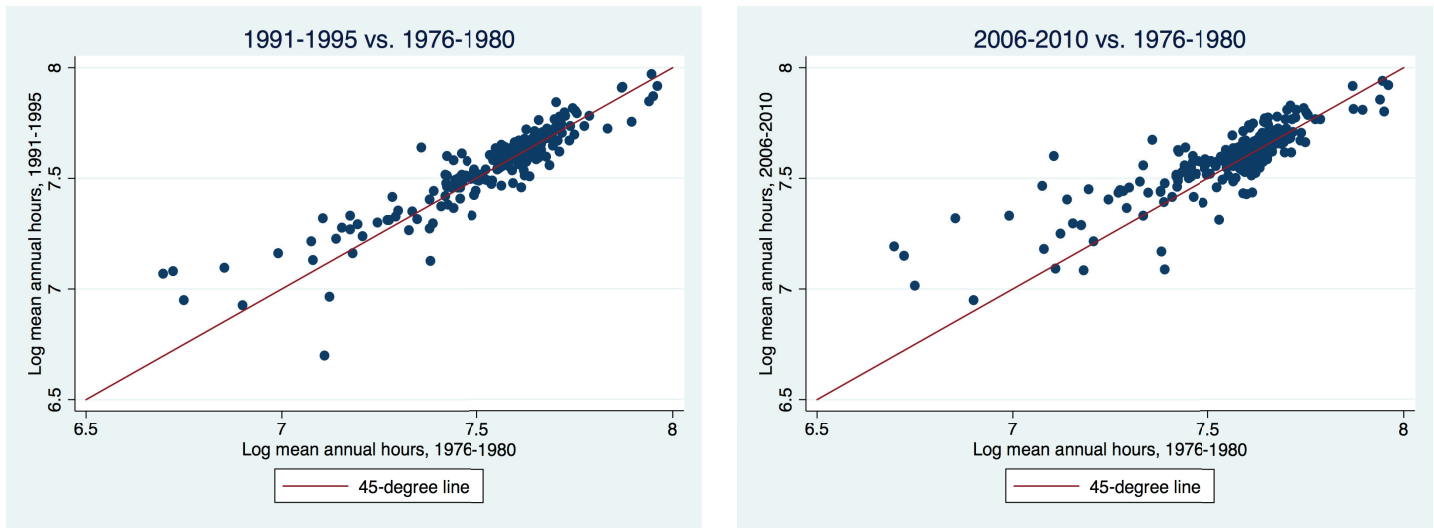

Notes: Each point represents a 3-digit occupation in a given 5-year time period. The scatter plot describes the change in log of mean annual hours in a given occupation over time, relative to the 1976-1980 period.

Figure 6 illustrates that the relative size of these occupations, in terms of the measure of men working in them, has also not changed much over time. We construct the complementary cumulative distribution function for men in period $t, \bar{F}_{m, t}(x)$, which is the probability that $X$ will take a value greater than $x$. We perform the analysis for two time periods $-1976-1980$ and 2006-2010 - and $x$ is either the log of male mean annual hours $(\ln \bar{h})$ in an occupation (left panel) or the standard deviation of male log annual hours $(s d \ln h)$ in an occupation (right panel) in that time period. The message from Figure 6 is that the distribution of men across occupations in the mean-dispersion hours space has been mostly stable during the 1976-2010 time period. There is an increase, although not very pronounced, in the fraction of men in occupations with higher mean hours and lower dispersion in hours: we see an increase in $\bar{F}_{m, t}(\ln \bar{h})$ for mean log occupational hours in the 7.2-7.5 interval (left panel) and a decrease in the $\bar{F}_{m, t}(s d \ln h)$ for standard deviation of log occupational hours in the 0.8-1.1 interval (right panel). 
Figure 5: Standard Deviation of Log Annual Hours, Men, Over Time: by 3-Digit Occupations.
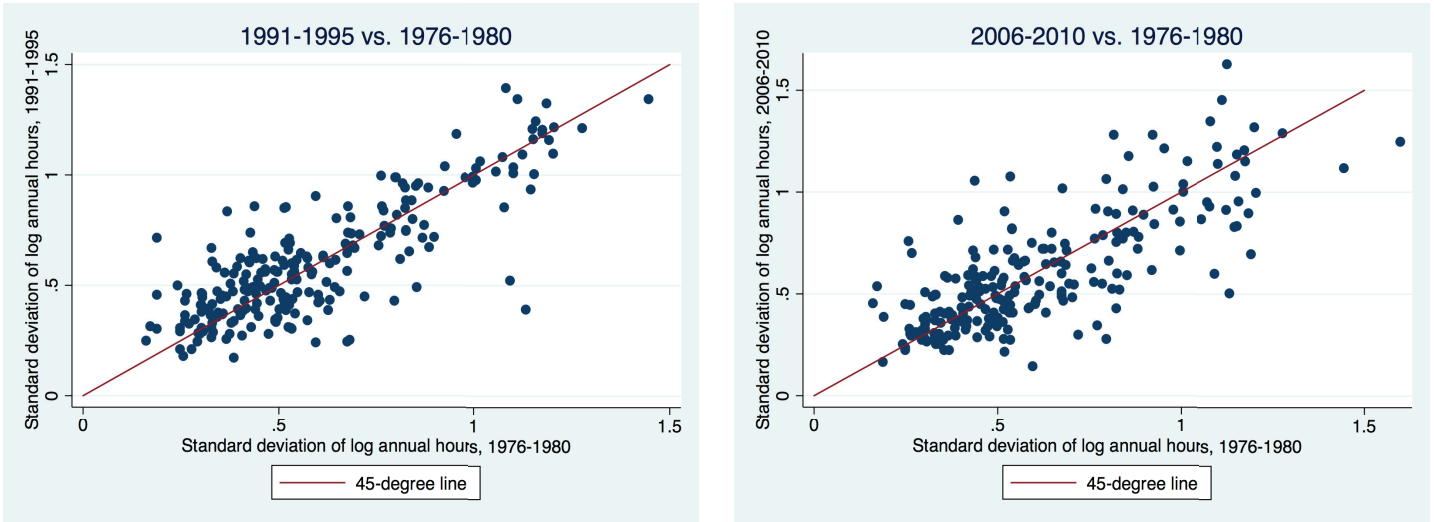

Notes: Each point represents a 3-digit occupation in a given 5-year time period. The scatter plot describes the change in the standard deviation of log annual hours in a given occupation over time, relative to the $1976-1980$ period.

Figure 6: Complementary Cumulative Distribution, Men: by 3-Digit Occupations.
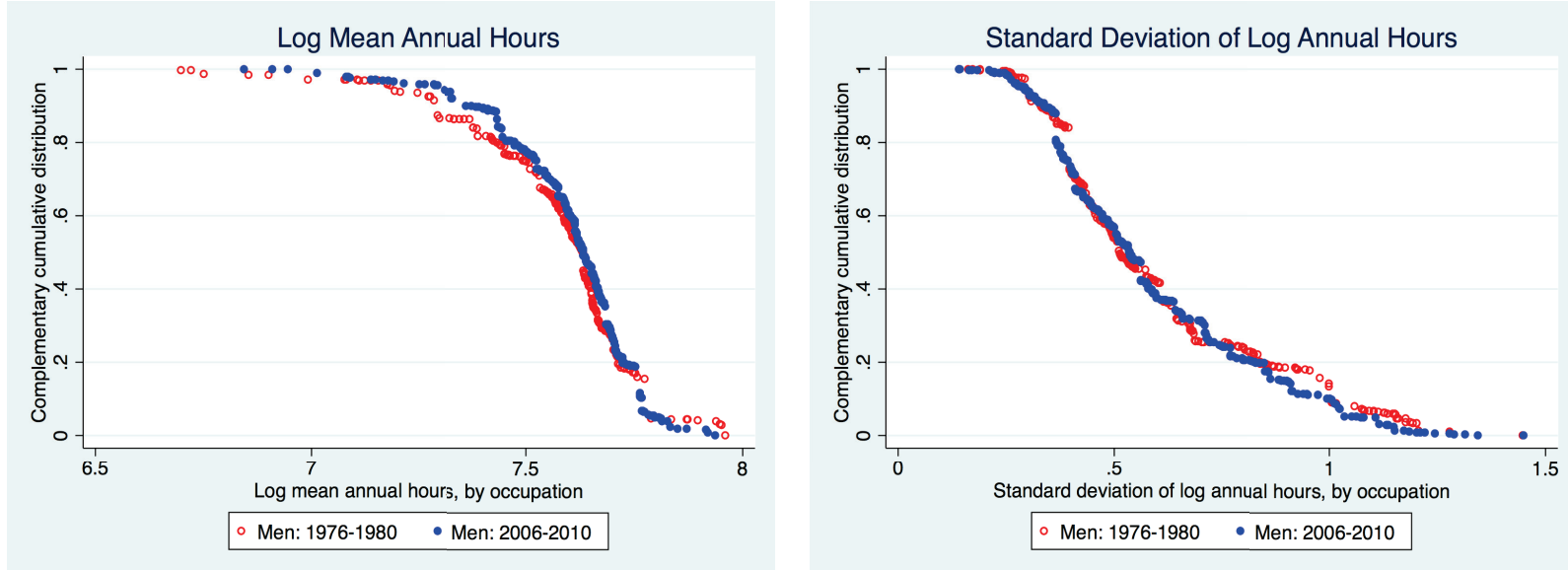

Notes: The scatter plots show the complementary cumulative distribution of men over occupations in terms of the log of male mean annual hours in an occupation (left panel) or the standard deviation of male log annual hours in an occupation (right panel) in the corresponding time period.

\subsubsection{Women}

The right panel in Figure 2 shows that we observe the same negative relationship between mean hours and the dispersion in hours for women. Moreover, the magnitude of the relationship is also similar. As Figure 7 shows, these patterns have slightly changed over time for women. 


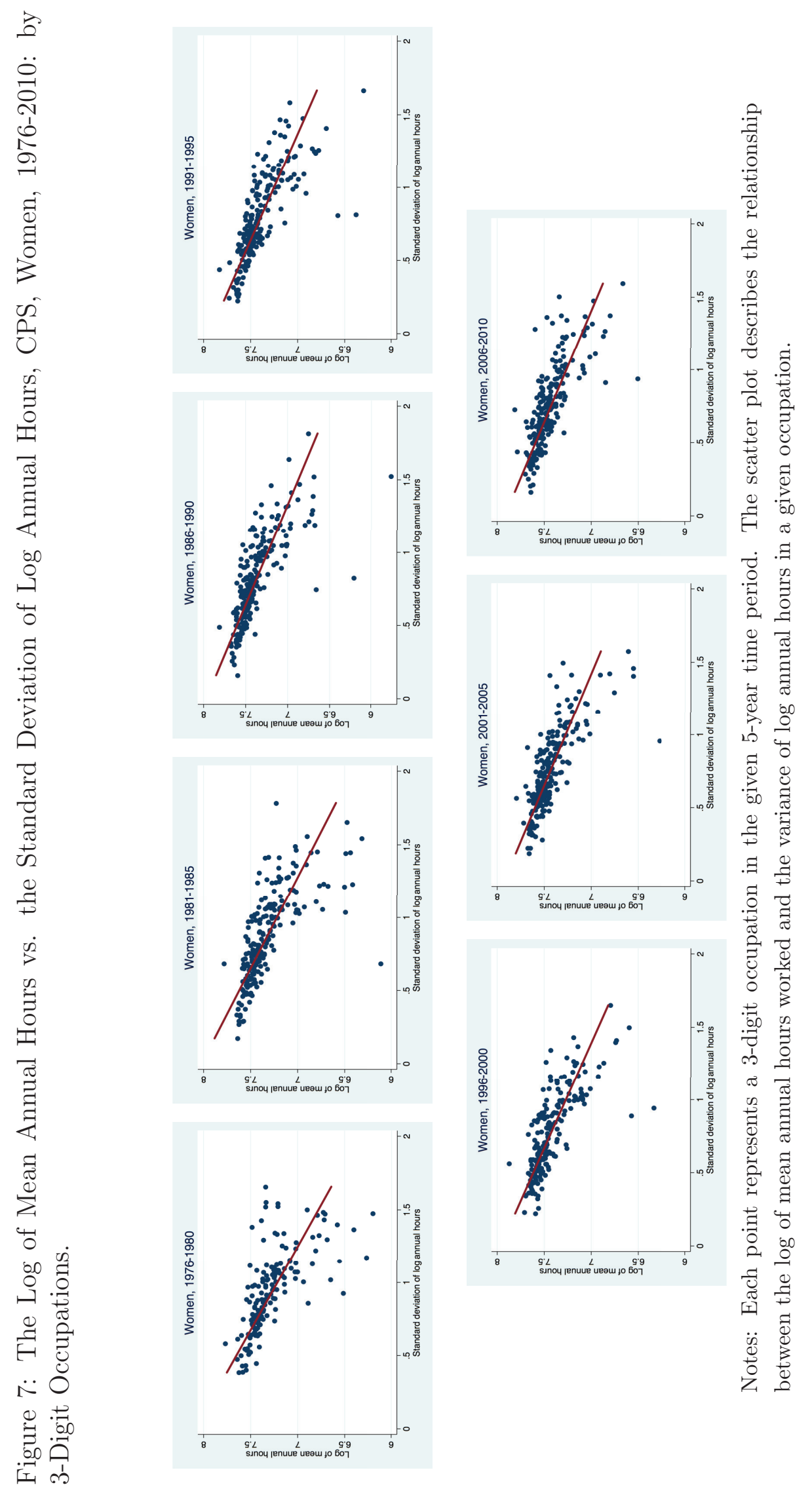


A key piece of information for our later analysis of gender differences will be the comparison of male and female labor supply conditional on occupation. Figure 8 shows that in almost all occupations women work less hours than men and have higher dispersion in hours worked than men.

Figure 8: Mean Annual Hours, Men vs. Women, CPS 1986-1995: by 3-Digit Occupations.
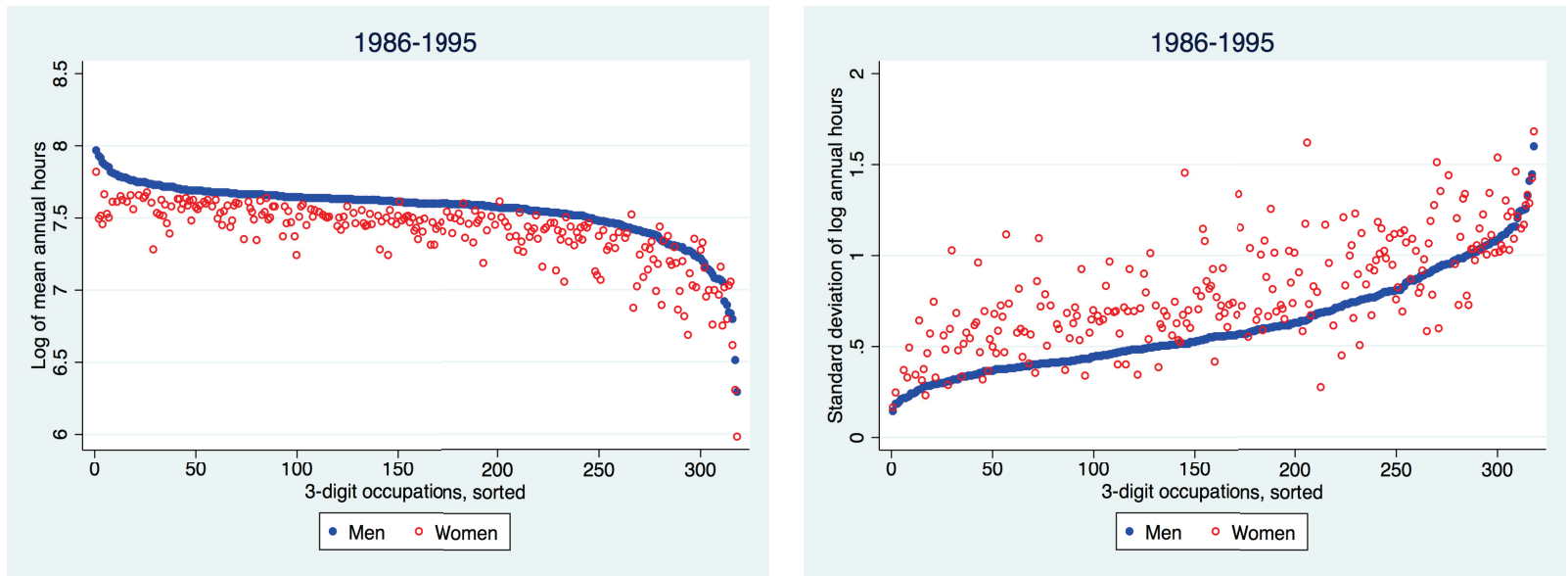

Notes: Each point represents a 3-digit occupation over the 1986-1995 time period. In the left panel, the solid dot (blue) scatter indicates, sorted from the highest to the lowest number, log mean annual hours worked for men in a given occupation, while the hollow dot (red) scatter indicates log mean annual hours worked for women in that same occupation. In the right panel, the solid dot (blue) scatter indicates, sorted from the lowest to the highest number, the standard deviation of log annual hours worked for men in a given occupation, while the hollow dot (red) scatter indicates the standard deviation of log annual hours worked for women in that same occupation.

In the previous subsection we found that the distribution of men across occupations in the mean-dispersion space has been relatively stable. In contrast, Figure 9 illustrates a dramatic shift in the distribution of women towards occupations with a higher mean and lower dispersion of hours. As in the previous subsection, we construct the complementary cumulative distribution function for women in period $t, \bar{F}_{f, t}(x)$, and perform the analysis for two time periods - 1976-1980 and 2006-2010 - where $x$ is either the log of female mean annual hours in an occupation (left panel) or the standard deviation of female log annual hours in an occupation (right panel) in that time period. For easy comparison with men, we replicate the $\bar{F}_{m, t}(x)$ for the 2006-2010 time period for men from Figure 6 . The main message that emerges from the analysis is a substantial shift of women towards occupations with a higher mean and lower dispersion in hours. Nevertheless, in 2006-2010 the distribution of women still differs from that of men: women are allocated in occupations with lower mean hours and higher dispersion in hours.

\subsection{Hourly Wages in Occupations}

In this subsection we examine the relationship between hourly wages and the position of an occupation in the space of mean hours and dispersion in hours. We present two results. First, 
Figure 9: Complementary Cumulative Distribution, Women: by 3-Digit Occupations.
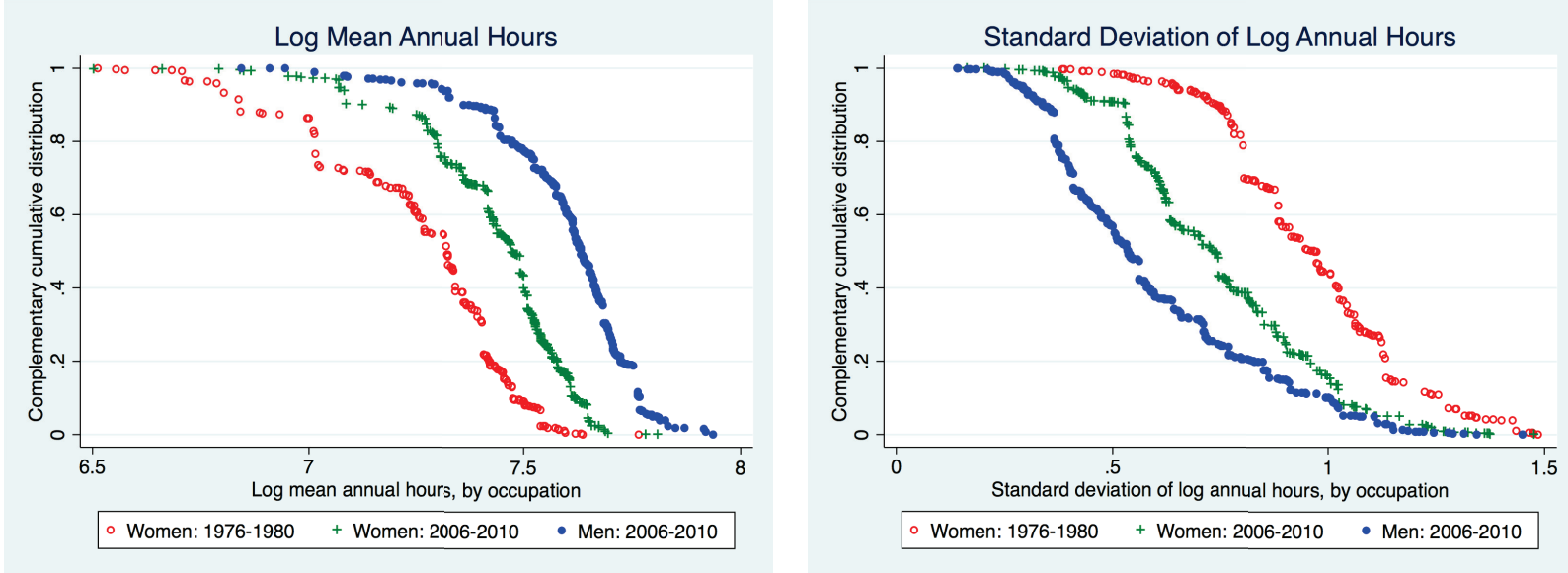

Notes: The scatter plots show the complementary cumulative distribution of women over occupations in terms of the log of female mean annual hours in an occupation (left panel) or the standard deviation of female log annual hours in an occupation (right panel) in the corresponding time period.

hourly wages decline on average as we move from the high-mean-low-dispersion occupations towards the low-mean-high-dispersion occupations. This is true both for men and women. Second, in most of the occupations, women receive lower hourly wages than men.

These general patterns are shown in Figure 10. The left panel plots the log mean hourly wages in an occupation for men, where occupations on the horizontal axis are inversely sorted by mean male annual hours in that occupation. ${ }^{9}$ On average, the hourly wages in the high mean hours occupations are significantly higher than in the low mean hours occupations. The right panel plots the log mean hourly wages in an occupation for women, where occupations on the horizontal axis are again inversely sorted by mean male annual hours in that occupation. Similar to the pattern observed for men the hourly wages for women, on average, in the high mean hours occupations are significantly higher than in the low mean hours occupations. Further, female hourly wages are lower than those for men. The bottom panel plots the log mean hourly wages in an occupation for both men (solid blue dots) and women (hollow red dots), where occupations on the horizontal axis are inversely sorted by the log of mean hourly wages for men in that occupation. In almost all occupations women receive lower hourly wages than men, and these differences are quantitatively quite substantial. ${ }^{10}$

\footnotetext{
${ }^{9}$ One could also sort based on the standard deviation of hours, but given that standard deviation will be measured with less precision we prefer to focus on the ranking based on mean hours.

${ }^{10}$ Albrecht, Bjorklund and Vroman (2003), using Swedish data in 1998, report that the gender wage gap in Sweden increases throughout the wage distribution. However, consistent with our findings, they do not find substantial differences in the gender wage gap throughout the wage distribution in US data in 1999.
} 
Figure 10: Log Mean Hourly Wages, Men vs. Women, CPS 1986-1995: by 3-Digit Occupations.
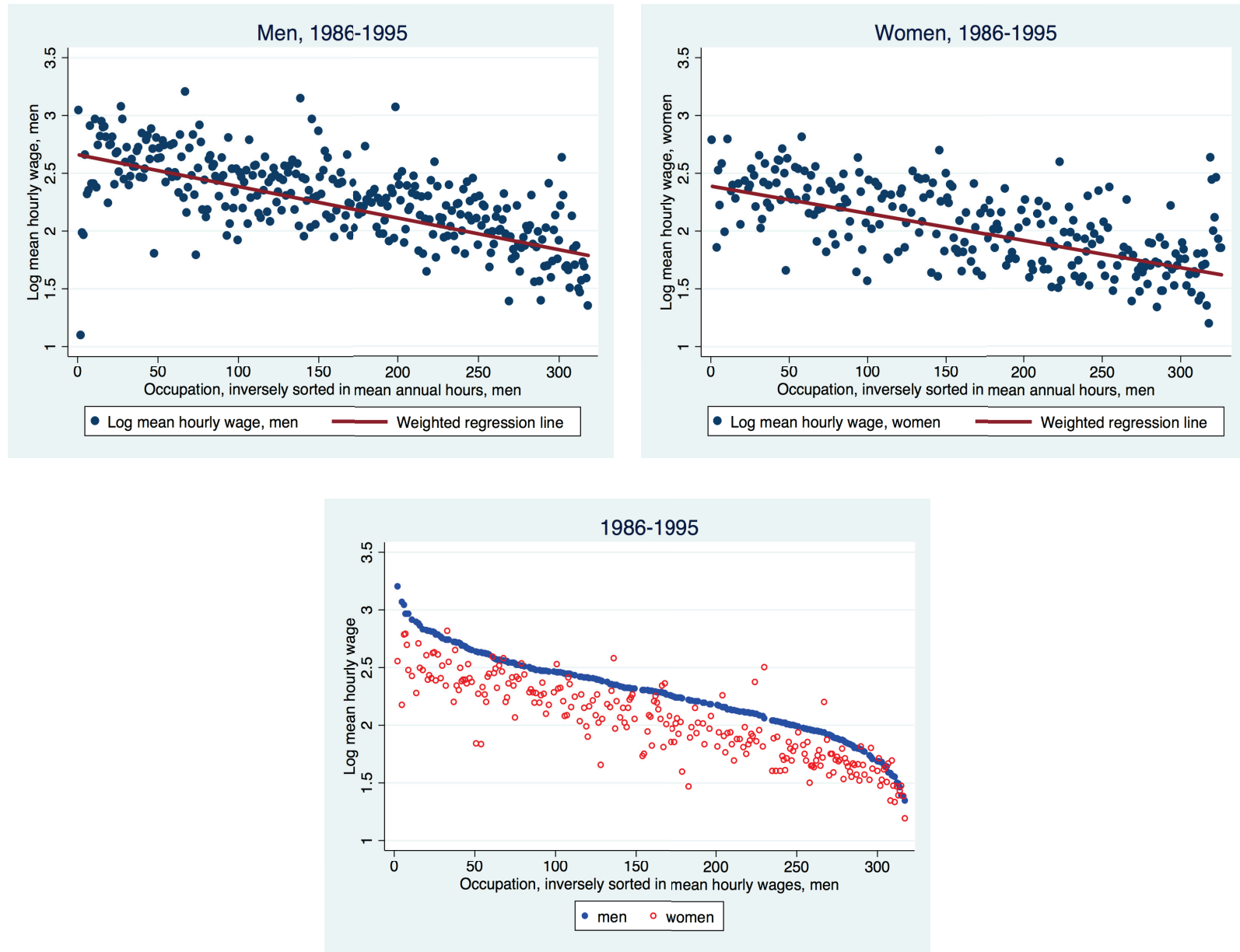

Notes: Each point represents a 3-digit occupation in the 1986-1995 time period.

\section{A Simple Benchmark Model}

In this section we develop a simple static benchmark model of occupational choice and hours worked. The core of the model is a standard two occupation version of the Roy (1951) model - individuals are endowed with differential productivity across occupations and heterogeneity of occupational comparative advantage leads them to sort across occupations.

We extend this model along three dimensions. First, we include a time allocation decision by assuming that individuals value leisure. Second, we add an additional dimension of heterogeneity by assuming heterogeneous preferences over leisure. Third, following Rosen (1978), we assume that the mapping from individual hours worked to the supply of efficiency units of labor is non-convex, generating a positive effect of hours worked on wages. Importantly, we assume that the extent of this non-convexity in technology is occupation-specific.

We show that this model can qualitatively account for the salient feature of the data shown in Figure 1. We then calibrate the model and show that the forces in the model 
can also deliver quantitative differences in the hours worked distributions across occupations that are similar to those in the data.

\subsection{Model}

There is a continuum of individuals of unit mass, indexed by $i$, with preferences over consumption $\left(c_{i}\right)$ and leisure $\left(T-h_{i}\right)$ given by:

$$
\ln c_{i}+\phi_{i} \frac{\left(T-h_{i}\right)^{1-\gamma}}{1-\gamma}
$$

where $T$ is the endowment of discretionary time and $h_{i}$ is hours of work for individual $i$. The preference parameter $\phi_{i}$ is assumed to vary across individuals, so that preference heterogeneity is included as a potential source for differences in hours of work. ${ }^{11}$ Each individual is endowed with a pair of occupational specific productivities, denoted by the pair $\left(a_{i 1}, a_{i 2}\right)$. Heterogeneity across individuals is thus described by the 3 -tuple $\left(a_{i 1}, a_{i 2}, \phi_{i}\right)$, and is assumed to be drawn from a multivariate log-normal distribution.

A single final good can be produced with two technologies, which we interpret as representing two different occupations. ${ }^{12}$ Each technology is linear in efficiency units of labor:

$$
Y_{j}=A_{j} E_{j}
$$

where $Y_{j}$ is total output from occupation $j$ and $E_{j}$ is the aggregate input of efficiency units of labor to occupation $j$.

The mapping from individual hours to efficiency units depends both on the idiosyncratic productivity of the individual and an occupation specific nonconvexity. If individual $i$ works $h_{i j}$ hours in occupation $j$ it generates efficiency units of labor $e_{i j}$ according to:

$$
e_{i j}=a_{i j} h_{i j}^{1+\theta_{j}}
$$

If $\theta_{j}=0$ we have the standard case in which the supply of efficiency units by an individual is linear in hours worked. Key for our analysis is that $\theta_{j}$ differs across occupations. For simplicity we assume $\theta_{1}=\theta>0=\theta_{2}$ so that only occupation 1 features a nonconvexity. In what follows we will refer to occupation 1 as the nonlinear occupation and to occupation 2 as the linear occupation. If we set $\theta=0$ our model is the Roy model extended to include an endogenous hours choice and heterogeneity in leisure. Our key modeling innovation is to extend this framework to allow for non-linear earnings where the non-linearity is heterogeneous across occupations.

We study the competitive equilibrium for this model. The economy features three markets: one for the final good and one for efficiency units of labor in each occupation. We normalize the price of the final good to unity, and given the linear production functions in

\footnotetext{
${ }^{11}$ It is well known that cross-sectional differences in wages are not sufficient to account for the crosssectional differences in hours. See, for example, Heathcote, Storesletten and Violante (2014).

${ }^{12}$ More generally we could assume two distinct intermediate goods, each produced by a different occupation, that are in turn combined into the single final good, but since for our purposes the additional layer adds little additional insight we have abstracted from it.
} 
each occupation, the competitive equilibrium price of an efficiency unit of labor will equal $A_{j}$. In what follows we will normalize the $A_{j}$ to unity. Solving for an equilibrium reduces to solving the individual optimization problem for each individual at these given prices and aggregating across the distribution of individuals.

\subsection{Qualitative Properties of Equilibrium}

The maximization problem of an individual can be written as:

$$
\begin{aligned}
& \max _{c, h_{j}, I}\left\{\ln c+\phi \frac{\left(T-\left[I h_{1}+(1-I) h_{2}\right]\right)^{1-\gamma}}{1-\gamma}\right\} \\
& \text { subject to: } \\
& c=I a_{1} h_{1}^{1+\theta}+(1-I) a_{2} h_{2}, I \in\{0,1\}, 0 \leq h_{j} \leq T
\end{aligned}
$$

where $I=1$ if individual works in occupation $1 .{ }^{13}$

Figure 11: Choice of $h$, Conditional on Occupation.

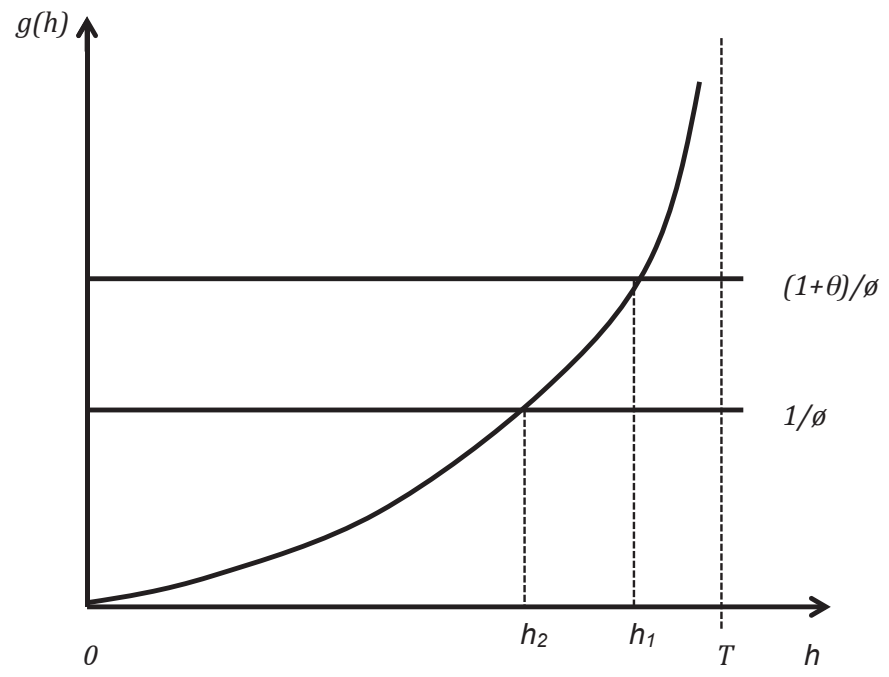

The choice of hours will necessarily be interior. If the individual chooses to work in occupation $j$, the optimal choice of hours $h_{j}$ satisfies:

$$
\frac{1+\theta_{j}}{\phi}=h_{j}\left(T-h_{j}\right)^{-\gamma} \equiv g\left(h_{j}\right)
$$

for $j=1,2$. The function $g$ defined in equation (3) is strictly increasing and convex (i.e., $\left.g^{\prime}, g^{\prime \prime}>0\right)$. Figure 11 offers a graphical illustration of this equation.

\footnotetext{
${ }^{13}$ This formulation assumes that the individual will only choose to work in one of the occupations, which is without loss of generality given the nature of the nonconvexity.
} 
Several properties follow. First, the $h_{j}$ are independent of the occupational productivities $a_{j}$ : an increase in productivity has an income and a substitution effect on labor supply that offset because of the specification of preferences. Second, and intuitively, since higher values of $\phi$ indicate a higher preference for leisure, each of the $h_{j}$ is decreasing in $\phi$. Third, as illustrated in Figure 11, conditional on a given value for $\phi, h_{1}$ is greater than $h_{2}$.

It follows that the cross-sectional variation in hours of work within an occupation is driven by the cross-sectional variation in the preference parameter $\phi$ for individuals in that occupation. As shown in Figure 11, because the function $g$ is convex, it is steeper in the vicinity of $h_{1}$ than it is in the vicinity of $h_{2}$. It follows that for a given variation in $\phi$, desired hours of work vary more in occupation 2 than in occupation 1.

This figure illustrates that holding the distribution of $\phi$ constant across occupations, we would get both higher mean hours and lower dispersion of hours in the non-linear occupation. The variation of $\phi$ across occupations in equilibrium depends on the sorting of individuals across occupations, which we discuss next.

An individual chooses to work in occupation 1 if the following inequality holds

$$
\ln \left(a_{1} h_{1}^{1+\theta}\right)+\phi \frac{\left(T-h_{1}\right)^{1-\gamma}}{1-\gamma}>\ln \left(a_{2} h_{2}\right)+\phi \frac{\left(T-h_{2}\right)^{1-\gamma}}{1-\gamma}
$$

where $h_{1}$ and $h_{2}$ represent the optimal hours of work in occupations 1 and 2 (i.e., they satisfy equation (3)). Recalling that the $h_{j}$ depend only on $\phi$ and not on the $a_{j}$, this expression can be re-arranged as:

$$
\ln \left(\frac{a_{1}}{a_{2}}\right)>z(\phi) \equiv-(1+\theta) \ln \left(h_{1}\right)+\ln \left(h_{2}\right)-\phi\left[\frac{\left(T-h_{2}\right)^{1-\gamma}}{1-\gamma}-\frac{\left(T-h_{1}\right)^{1-\gamma}}{1-\gamma}\right] .
$$

Thus, an individual chooses to work in occupation 1 if the $\log$ of their skill ratio $\frac{a_{1}}{a_{2}}$ is higher than $z(\phi)$. An important feature of our model is that occupational choice is determined both by comparative advantage and taste for leisure. In a standard Roy model extended to include a leisure choice, occupational choice would solely be determined by comparative advantage.

The probability that an individual with a taste for leisure $\phi$ works in occupation 1 is given by:

$$
P(I=1 \mid \phi)=P\left[\ln \left(\frac{a_{1}}{a_{2}}\right)>z(\phi)\right] .
$$

Using $h_{j}=\frac{1+\theta}{\phi}\left(T-h_{j}\right)^{\gamma}$ from $(3)$ and $\frac{d h_{1}}{d \phi}<0$, one can show that:

$$
z^{\prime}(\phi)=-2 \frac{\phi}{1+\theta}\left(T-h_{1}\right)^{\gamma} \frac{d h_{1}}{d \phi}>0
$$

Consider the special case in which taste for leisure is independent of comparative advantage, i.e., the ratio $\frac{a_{1}}{a_{2}}$. In this case (6) and (7) imply that the probability of working in occupation 1 is decreasing in $\phi$. In other words, individuals with a low taste for leisure ( $\phi$ low) are more likely to work in occupation 1. Since hours in occupation 1 are higher than hours in occupation 2 even for a fixed value of $\phi$, this selection effect amplifies the differences in hours worked in the two occupations. Additionally, since individuals working in occupation 
1 are more likely to be selected from those who work long hours, the convexity of $g$ creates a force making the dispersion of hours in occupation 1 small relative to that of occupation 2 . Having low $\phi$ individuals sort systematically into the non-linear occupation would tend to decrease the variance of $\phi$ within each occupation, and the effect on relative levels of variance is unclear.

The basic intuition about mean and dispersion of hours across occupations is potentially undermined when the taste for leisure is more (positively) correlated with ability in occupation 1 than in occupation 2. In this case the difference in mean hours between the two occupations will be smaller than in the case of uncorrelated shocks and the difference in the variance of hours across occupations will diminish. Conversely, the opposite will happen if taste for leisure is less correlated with ability in occupation 1 than in occupation 2 . In our model all of the individual parameters are assumed to be exogenous. In a richer model in which individuals make choices to invest in skills that might differentially affect their productivity in the two occupations, the model contains a force that serves to make it more attractive for individuals with lower values of $\phi$ to invest relatively more in skills that lead to higher productivity in occupation 1.

We conclude that the basic economic forces captured by our model can qualitatively generate the negative correlation across occupation measures of mean hours and dispersion of hours.

\subsection{A Quantitative Assessment}

In this section we assess the extent to which the forces emphasized in the previous subsection are relevant for thinking about the quantitative differences depicted in Figure 1. In order to highlight the role of the novel feature of our analysis-the heterogeneity in return to working longer hours across occupations-we purposefully restrict the Roy model parameters to be symmetric with regard to occupations. This allows for a very transparent assessment of the extent to which asymmetry in $\theta$ across occupations can generate quantitative differences in the properties of hours of work across occupations similar to those found in the data.

Specifically, we assume that $a_{1}, a_{2}$, and $\phi$ are independently distributed across the population and that $\sigma_{a_{1}}=\sigma_{a_{2}}$. Adjusting the means of the idiosyncratic productivities is equivalent to adjusting the $A_{j}$ terms in the occupational production functions. To minimize notation we normalize both of the $A_{j}$ equal to unity. Additionally, we normalize the mean of $\ln \left(a_{1}\right)$ to zero, as this effectively represents a choice of units, and will use the mean of $\ln \left(a_{2}\right)$ to ensure that we end up with equal employment in the two occupations. ${ }^{14}$

Although we will interpret our model as reflecting lifetime outcomes, consistent with our data analysis we will report labor supply measures in terms of annual hours. As a result we set the (discretionary) time endowment to 5200 hours. We set $\gamma=4$, so that the intertemporal elasticity of leisure along the intensive margin is fixed at a value of $1 / 4 .{ }^{15}$

\footnotetext{
${ }^{14}$ Equivalently, we could have set the mean of $\ln \left(a_{2}\right)$ equal to zero to preserve perfect symmetry and then adjusted the value of $A_{2}$ to secure equal employment in the two occupations. Since these are equivalent we chose our approach since it allows us to simply abstract from considering the values of the $A_{j}$.

${ }^{15}$ In terms of averages, we will assume that leisure is $60 \%$ of total discretionary time and that work is the remaining $40 \%$, so that evaluated at the average values the corresponding intertemporal elasticity of substitution for work along the intensive margin is roughly .4, in line with standard values assumed in the
} 
A key parameter for our analysis is $\theta$, as this determines the extent of asymmetry across occupations in terms of the return to working longer hours. We want this choice to reflect both the static and dynamic effects of longer hours on earnings. There is a substantial amount of evidence on the average effects of hours on earnings. (For evidence on the static effects, see the summary in Erosa, Fuster and Kambourov (2016a). For evidence on dynamic effects, see, for example, Imai and Keane (2004).) Key for our purposes is the variation in these effects across occupations. While definitive estimates of these differences are not available, several papers present relevant evidence. Goldin (2014) and Cortés and Pan (2017b) offer some evidence on cross-sectional variation for a subset of occupations in the US. ${ }^{16}$ Sullivan (2010) presents evidence using the U.S. 1979 National Longitudinal Survey of Youth (NLSY) while Zangelidis (2008) presents evidence for the UK. Dustmann and Meghir (2005) present estimates for variation across different skill groups. Based on the evidence from this literature we choose $\theta=0.6$ for our baseline calibrations. See Appendix $\mathrm{C}$ for more details regarding this choice. But given the lack of a definitive estimate for this important parameter, we also report results for alternative values.

Since the simple benchmark model consists of only two occupations, we aggregate the data into two occupations: we rank all occupations in the 1986-1995 CPS according to their mean hours worked and separate them into two groups that are equal in size. ${ }^{17}$ Four parameters remain to be calibrated: mean ability in occupation $2\left(\mu_{a_{2}}\right)$, the mean and the variance of the distribution of (log) taste for leisure $\left(\mu_{\phi}\right.$ and $\left.\sigma_{\phi}\right)$, and the common variance of the occupation productivities $\left(\sigma_{a_{2}}=\sigma_{a_{1}}\right)$. Because our goal in this section is to assess the ability of our model to generate asymmetric outcomes across occupations like those found in the data, we will assign values for all of these parameters so as to target properties of aggregate outcomes. Having targeted aggregate moments by design, we focus on whether the model can generate differential outcomes across occupations similar in magnitude to those found in the data.

Table 1: Calibration, Simple Benchmark Model.

\begin{tabular}{lllll}
\hline \hline Parameter & Value & Target & Data & Model \\
\hline$\mu_{a_{2}}$ & -0.0572 & $E^{N L} / E^{L}$ & 1.00 & 1.00 \\
$\sigma_{a_{2}}^{2}$ & 0.3456 & $s d(\ln w)$ & 0.50 & 0.50 \\
$\mu_{\phi}$ & 0.9243 & $\ln \bar{h}$ & 7.54 & 7.54 \\
$\sigma_{\phi}^{2}$ & 1.1417 & $s d(\ln h)$ & 0.38 & 0.38 \\
\hline \hline
\end{tabular}

literature.

${ }^{16}$ See Bertrand et al. (2010) for evidence on individuals with MBAs, and Gicheva (2013) for a sample of individuals who took the GMAT. See also Adda et al. (2017).

${ }^{17} \mathrm{~A}$ detailed description of the dataset, the sample restrictions, and the approach for obtaining the moments on the mean and dispersion in hours and wages - overall and by occupation - is provided in Appendix A. 
Table 2: Simple Benchmark Model.

\begin{tabular}{|c|c|c|c|c|c|}
\hline \multicolumn{6}{|c|}{ Data } \\
\hline & Emp. share & Log mean hours & Std log hours & Log mean wages & Std log wages \\
\hline Non-Linear & 0.50 & 7.65 & 0.29 & 2.39 & 0.49 \\
\hline Linear & 0.50 & 7.41 & 0.47 & 1.91 & 0.51 \\
\hline Aggregate & 1.00 & 7.54 & 0.38 & 2.21 & 0.50 \\
\hline \multicolumn{6}{|c|}{ Model } \\
\hline & Emp. share & Log mean hours & Std log hours & Log mean wages & Std log wages \\
\hline Non-Linear & 0.50 & 7.66 & 0.29 & 2.25 & 0.50 \\
\hline Linear & 0.50 & 7.41 & 0.41 & 2.17 & 0.49 \\
\hline Aggregate & 1.00 & 7.54 & 0.38 & 2.21 & 0.50 \\
\hline
\end{tabular}

The four moments that we target and the implied parameter values are listed in Table 1. While the values of these four parameters are jointly determined by the four moments, it is natural to identify each calibrated parameter with a particular moment that it affects in a very direct way. The mean of $\phi$ is intimately related to the mean level of hours, and dispersion of hours is intimately related to dispersion in $\phi$. With this in mind we choose $\mu_{\phi}$ so that the $\log$ of mean hours is equal to 7.54 and choose $\sigma_{\phi}$ so that the standard deviation of $\log$ hours is equal to 0.38 . Finally, dispersion in productivity will be intimately related to dispersion in wages, so $\sigma_{1}$ (and hence $\sigma_{2}$ ) is chosen to match a variance of log wages of 0.50. The calibrated model economy matches these four targets perfectly.

Outcomes for the calibrated model are displayed in Table 2. The model captures the differences in mean log hours of work across occupations almost perfectly: in the model the values are 7.66 in the non-linear occupation and 7.41 in the linear occupation, while the corresponding values in the data are 7.65 and 7.41. The model also accounts for roughly twothirds of the variation in dispersion found in the data: in the model the standard deviation of hours in the non-linear and linear occupations are 0.29 and 0.41 , whereas the corresponding values in the data are 0.29 and 0.47 .

Both in the model and in the data the dispersion of wages within occupations is virtually identical across occupations. While the model does generate a higher average wage in the non-linear occupation, it accounts for only about one-sixth of the gap in the data: 8 log points in the model versus $48 \log$ points in the data. We do not view this as a weakness of the model. One of the known and desirable features of the Roy model is that it can generate wage differences across occupations via selection effects. Assuming a positive correlation between comparative advantage in the non-linear occupation and absolute advantage will generate higher wages in the non-linear occupation. The above exercise abstracted from this in order to focus on the asymmetric effects due purely to $\theta$. In our quantitative analysis later in the paper we will relax the restrictions on the Roy model parameters.

Table 3 highlights the selection effects in the model due to the differences in $\theta$ across occupations. The first three columns show the intuitive result of selection based on compar- 
Table 3: The Role of Selection in the Simple Benchmark Model.

\begin{tabular}{lccccc}
\hline \hline & $\ln \left(\overline{a_{1}}\right)$ & $\ln \left(\overline{a_{2}}\right)$ & $\ln \overline{\left(\frac{a_{1}}{a_{2}}\right)}$ & $\ln (\bar{\phi})$ & $s d(\ln \phi)$ \\
\cline { 2 - 5 } Non-Linear & 4.93 & 4.18 & 0.74 & 24.92 & 1.02 \\
Linear & 4.28 & 4.82 & -0.53 & 25.32 & 1.08 \\
Aggregate & 4.61 & 4.50 & 0.11 & 25.12 & 1.07 \\
\hline \hline
\end{tabular}

ative advantage, as in a standard Roy model. The fourth column shows the novel selection effect present in our model: even though the preference for leisure is uncorrelated with comparative advantage in our calibration, we see that preference for leisure is higher among those individuals who work in occupation 2. As a result of this selection, we see that the dispersion of tastes for leisure is somewhat smaller in occupation 1 than in the aggregate, thus reinforcing the tendency for hours worked to be less dispersed in occupation 1.

We have also repeated this exercise for $\theta=0.4$ and $\theta=0.8$. Although the crossoccupational effects are increasing in the magnitude of $\theta$, the effects are fairly similar for this range. Specifically, moving to $\theta=0.8$ increases the effects on mean and standard deviation of hours very marginally, but increases the occupational wage gap to $17 \%$. Moving to $\theta=0.4$ reduces the gap in mean occupational hours by about a quarter (from .25 to .18) and also decreases the gap in the standard deviation of hours across occupations similarly (from .12 to .09). In this case the occupational wage gap is reduced to $4 \%$.

In summary, our main takeaway from this section is that the forces captured in our simple model can provide the basis for a quantitative model of occupational choice and labor supply.

\section{Multi-Member Households}

We are particularly interested in using our framework to understand the forces that shape gender differences in labor market outcomes, and for this reason we extend our model to explicitly include males and females. Because most labor supply takes place in a household setting, we adopt a household model of labor supply in which households consist of one male and one female. As we will see, tradeoffs within the household will play an important role in shaping occupational choices and hours worked by gender, so the assumption of multimember households as opposed to single agent households is important.

The extension of the model is straightforward. There is a unit mass of households, each composed of a male $(m)$ and a female $(f)$. We assume a unitary household model in which the household has preferences over the weighted sum of the utilities of its two members as 
given $\mathrm{by}^{18}$ :

$$
U\left(c_{m}, c_{f}, h_{m}, h_{f}\right)=\alpha_{m} u_{m}\left(c_{m}, h_{m}\right)+\alpha_{f} u_{f}\left(c_{f}, h_{f}\right)
$$

where

$$
\begin{aligned}
& u_{g}\left(c_{g}, h_{g}\right)=\ln c_{g}+\phi_{g} \frac{\left(T_{g}-h_{g}\right)^{1-\gamma}}{1-\gamma} \text { for } g=m, f \\
& \alpha_{m}+\alpha_{f}=2
\end{aligned}
$$

where $\alpha_{g}$ is the Pareto weight in the household utility function for member $g$ while $T_{g}$ and $h_{g}$ are the discretionary time endowment and hours of work for the member of gender $g$, implying that $T_{g}-h_{g}$ is the leisure for member $g .{ }^{19}$ We allow for differences in endowments of discretionary time as a way to capture differences in responsibilities at home for activities like child care and other home production tasks. The parameters $\phi_{m}$ and $\phi_{f}$ represent idiosyncratic tastes for leisure. Each member of the household is now endowed with a pair of occupational specific productivities, denoted by the pair $\left(a_{g 1}, a_{g 2}\right)$. The heterogeneity across households is thus described by the 6-tuple $\left(a_{g 1}, a_{g 2}, \phi_{g}\right)_{g=m, f}$, which is assumed to be drawn from a multivariate log-normal distribution. We allow for the possibility that the household does not equally weight each member's utility. The reason for this will become clear later. ${ }^{20}$

The technology is exactly as before. It remains true that in competitive equilibrium all three prices are equal and can be normalized to unity, so solving for an equilibrium reduces to the problem of solving for the choices of each household at these given prices and aggregating across the distribution of households.

We define a set of indicator functions $\left(I_{1}^{g}, I_{2}^{g}\right)$, where $I_{j}^{g}$ takes the value of 1 if the individual of gender $g$ chooses to work in occupation $j=1,2 .{ }^{21}$ The household problem becomes:

$\max \left\{\alpha_{m} \ln c_{m}+\alpha_{f} \ln c_{f}+\alpha_{m} \phi_{m} \frac{\left(T_{m}-\left[I_{1}^{m} h_{m 1}+I_{2}^{m} h_{m 2}\right]\right)^{1-\gamma}}{1-\gamma}+\alpha_{f} \phi_{f} \frac{\left(T_{f}-\left[I_{1}^{f} h_{f 1}+I_{2}^{f} h_{f 2}\right]\right)^{1-\gamma}}{1-\gamma}\right\}$

subject to:

$c_{m}+c_{f}=\left\{\sum_{j=1}^{2} I_{j}^{m} a_{m j} h_{m j}^{1+\theta_{j}}+\sum_{j=1}^{2} I_{j}^{f} a_{f j} h_{f j}^{1+\theta_{j}}\right\}$.

\footnotetext{
${ }^{18}$ There is a large literature on labor supply in non-unitary household models. An early and important contribution is Chiappori (1992). See also the survey in Chiappori and Donni (2011). While we think it is of interest to consider the collective model of household choice, we leave this extension for future work.

${ }^{19}$ Given our specification of log utility, allowing for economies of scale in consumption would have no effect on our analysis. We abstract from them to better facilitate a comparison with a version of the model that considers single individual households. This same consideration motivates our decision to have the Pareto weights sum to two instead of one.

${ }^{20}$ More generally we could allow these weights to differ exogenously across households based on household characteristics, or to be determined endogenously through some bargaining protocol. We feel our simpler approach is most appropriate for our exercise.

${ }^{21} \mathrm{As}$ in the single individual household model, it remains true that it is without loss of generality to assume that an individual works in at most one occupation. While it is necessarily true that at least one individual in the household will work, it is now possible that one of the individuals will not work, in which case both indicator functions take on the value of 0 for that individual.
} 
The optimal allocation of consumption implies that consumption by the male and female are given by $c_{m}=\alpha_{m} c, c_{f}=\alpha_{f} c$, where $c=\frac{c_{m}+c_{f}}{2}$ represents the average consumption across household members. Using this fact, the optimal choice of hours for the two individuals conditional on occupational choices satisfy the following first order conditions:

$$
\begin{aligned}
& \frac{a_{m j}\left(1+\theta_{j}\right) h_{m j}^{\theta_{j}}}{a_{m j} h_{m j}^{1+\theta_{j}}+a_{f i} h_{f i}^{1+\theta_{i}}}=\alpha_{m} \phi_{m}\left(T_{m}-h_{m j}\right)^{-\gamma}, \\
& \frac{a_{f i}\left(1+\theta_{i}\right) h_{f i}^{\theta_{i}}}{a_{m j} h_{m j}^{1+\theta_{j}}+a_{f i} h_{f i}^{1+\theta_{i}}}=\alpha_{f} \phi_{f}\left(T_{f}-h_{f i}\right)^{-\gamma},
\end{aligned}
$$

where $j$ and $i$ are the occupational choices for the male and female respectively. Each worker equates the disutility of working one more hour to the marginal increase in earnings multiplied by the marginal utility of household consumption. The effects noted in Section 3 remain: holding the other member's choices fixed, hours are decreasing in the value of $\phi$ and choosing the non-linear occupation implies higher hours. But because household consumption is determined by the sum of the earnings of the two individuals, the earnings of one spouse now have an income effect on the labor supply of the other household member.

Cross-effects on hours of work is a standard feature of any multimember household model. The novel feature of our analysis is that these income effects also influence occupational choices: if one member chooses to work in occupation 1, thereby working longer hours and hence generating more income, this decreases the marginal utility of income earned by the second member and makes it less likely that this individual will work in occupation 1 . That is, there are also cross-effects on occupational choice. This discussion points to the fact that the correlations of skills and the taste for leisure across spouses is potentially important for household decisions. It will therefore be important that our quantitative analysis include empirically reasonable values for these correlations.

\section{Quantitative Analysis}

We believe the above model represents an interesting framework for examining how various factors shape gender differences in labor market outcomes. Our main goal in this section is to use the model to quantitatively assess one particular source of gender differences in labor market outcomes. In particular, we study the extent to which gender asymmetries in non-market responsibilities (e.g., child care, home production activities) can lead to gender asymmetries in market outcomes such as wages, hours of work and occupational choice. To do this we study the consequences of exogenous gender asymmetries in the endowment of discretionary time. While it is clearly important to understand the causes of this asymmetry, we think it is also of independent interest to understand its consequences for market outcomes. In the current context we feel that these consequences can be isolated more effectively and transparently by taking the non-market asymmetry as exogenous.

Before proceeding to the quantitative analysis, it is instructive to summarize the mechanisms at work in our model from a qualitative perspective to better appreciate the channels that our analysis will quantify. These qualitative effects are intuitive: if women have fewer hours of discretionary time, the direct effect is for them to work fewer hours in the market. 
Conditional on working in occupation 1, this penalizes them in terms of hourly wages owing to the positive effect of hours worked on the wage rate. Because a decline in hours is more costly in occupation 1 than in occupation 2, this decrease in discretionary time also distorts the occupational choice of women, generating selection effects. ${ }^{22}$ These selection effects serve to increase the average quality of females in occupation 1 and decrease the average quality of females in occupation 2. Through intra-household effects, these effects on female choices impact male choices, which in turn amplify the direct effects on female choices. Our analysis will quantify not only the overall effect but also the relative importance of these various components. ${ }^{23}$

An issue that will influence our empirical strategy is that other asymmetries in the overall economic environment may influence how the asymmetry in nonmarket allocations is propagated into market outcomes. For this reason we will explicitly include two additional sources of asymmetry in our analysis. One of these will capture factors that are not part of our mechanism but which serve to depress relative market wages of women. Importantly, through the mechanism described above, our model generates gender wage gaps over and above any exogenously specified gender wage gap, and our analysis will focus on these additional effects. The second will reflect gender weights in the household utility function. The role of this second wedge will become clearer when we discuss the calibration procedure.

\subsection{Calibration}

In this subsection we present our baseline calibration. We proceed in two steps. In the first step we describe how we aggregate the data on occupational outcomes into two occupations. Having done this we describe how we choose parameter values for the calibrated model.

\subsubsection{Aggregating the Data to Two Occupations}

A key part of the calibration exercise will involve using moments from occupational differences in the distributions of wages and hours worked. Because our model contains only two occupations, this requires that we aggregate the data into two occupations. Since our benchmark model is a model of couples, we restrict the sample to married individuals aged between 22 and 64 when computing moments to be used in the calibration. In order to form the two occupational groupings we compute the mean hours worked for men in each occupation, rank all occupations by the level of mean hours of men, and separate them into two groups that are equal in size (men plus women), based on person-level weights. Conditional on this classification, we compute the fraction of men and women employed in the linear and the non-linear occupations. Further, we compute the mean and the dispersion in hours and wages for men and women - overall and in each of the two occupations. Appendix A

\footnotetext{
${ }^{22}$ Wasserman (2017) uses a quasi-natural experiment involving hours of medical residents to provide evidence that long hours influence occupational choices for women.

${ }^{23}$ As noted earlier, our analysis focuses on one assessing the implications of one specific source of asymmetry. The literature has also emphasized other potential sources of gender asymmetry. For example, as explored in Buser, Niederle and Oosterbeek (2014) women may have different preferences over working in occupations relative to men. See Cortés and Pan (2017a) for a more complete discussion of alternatives. We view our analysis as complementary to these explanations.
} 
provides a detailed description of the variables used in the analysis, the sample restrictions imposed throughout, and the exact procedure for obtaining the moments of interest.

The corresponding moments of interest are reported in Table 4. The following patterns are worth pointing out.

Men. (i) Men are disproportionately employed in the non-linear occupation: 61\%, (ii) Male hours in the non-linear occupation are 16 log points higher than in the linear occupation; (iii) The dispersion in male hours is 10 log points higher in the linear occupation; (iv) Male hourly wages are 37 log points higher in the non-linear occupation; and (v) The dispersion in male wages is similar in the non-linear and the linear occupation.

Women. (i) The share of women employed in the non-linear occupation is substantially below one half: 37\%; (ii) Female hours in the non-linear occupation are 16 log points higher than in the linear occupation; (iii) The dispersion in female hours is 11 log points higher in the linear occupation; (iv) Female hourly wages are 35 log points higher in the non-linear occupation; and (v) The dispersion in female wages is similar in the non-linear and the linear occupation.

Gender differences. (i) Mean hours for women are 27 log points less than for men; (ii) The dispersion in hours worked is 20 log points higher for women than for men; (iii) Female hourly wages are $42 \log$ points lower than male hourly wages, and the gender wage gap is similar in both occupations - 35 log points in the non-linear occupation and 33 log points in the linear occupation; and (iv) The dispersion in hourly wages is similar for men and women.

Table 4: Data Moments: CPS (1986-1995).

\begin{tabular}{lccccc}
\hline \hline \multicolumn{5}{c}{ Males } \\
& \multicolumn{5}{c}{} \\
& Emp. share & Log mean hours & Std log hours & Log mean wages & Std log wages \\
\hline Non-Linear & 0.61 & 7.73 & 0.22 & 2.56 & 0.45 \\
Linear & 0.39 & 7.57 & 0.32 & 2.19 & 0.46 \\
Aggregate & 1.00 & 7.67 & 0.26 & 2.46 & 0.45 \\
\hline
\end{tabular}

Females

\begin{tabular}{lccccc} 
& Emp. share & Log mean hours & Std log hours & Log mean wages & Std log wages \\
\hline Non-Linear & 0.37 & 7.49 & 0.39 & 2.21 & 0.49 \\
Linear & 0.63 & 7.33 & 0.50 & 1.86 & 0.47 \\
Aggregate & 1.00 & 7.40 & 0.46 & 2.04 & 0.48 \\
\hline \hline
\end{tabular}

As discussed in Appendix A, we use the PSID to compute the spousal correlations in hourly wages and annual hours worked - two important identifying moments in the model. The estimated correlation in spousal log wages is 0.43 and in spousal log hours 0.02 . 


\subsubsection{Setting Parameter Values}

Parameters assigned without solving the model. We assign values for $T_{m}, T_{f}, \gamma$ and $\theta$ without solving the model. As in Section 3 we will measure labor supply variables at annual frequency and accordingly will set $T_{m}$ to 5200, implying 100 hours of discretionary time per week. The time endowment of females is set to 4700 hours. This amounts to gender differences in time endowment of about ten hours per week, which is consistent with average gender differences for hours spent in home production in the American Time Use Survey (ATUS). As in Section 3, we set $\gamma=4$ and $\theta=0.6$, and will consider alternative values for $\theta$ in our sensitivity analysis.

Parameters assigned by solving the model. It remains to assign the parameters for the population distribution of the idiosyncratic productivity and preference parameters, the correlation of these parameters among spouses, and the Pareto weights in the household objective function. In principle, the data would allow us to estimate the distributional parameters without placing too many a priori restrictions. While we think it is worthwhile to pursue this route, at this point we adopt the alternative approach of starting with a somewhat minimalist specification with relatively fewer free parameters. We think this is of interest for two reasons. First, we believe it creates more transparency in terms of understanding the moments that are providing identification. Second, as we will see, our current specification is able to match what we view as the most salient features of the data. Having said this, we view our current effort to quantify the mechanisms in the model as a reasonable starting point.

With this in mind, we adopt the following distributional assumptions. First, and without loss of generality, the mean value of log-ability in occupation 1 is normalized to zero. Second, we impose that the underlying distribution of the $a_{j}$ 's and $\phi_{j}$ 's do not vary across males and females except for a uniform (across occupations) skill gap. ${ }^{24}$ We make this assumption so that our main exercise can be understood as shedding light on the ability of our mechanism to create asymmetries across groups with identical population characteristics. Additionally, we impose that productivity draws are uncorrelated with preferences for leisure (i.e., $\rho_{a_{1}, \phi}=$ $\left.\rho_{a_{2}, \phi}=0\right)$, and that the correlation of $a_{1}$ between spouses is the same as the correlation of $a_{2}$ among spouses (i.e., $\rho_{a_{1 m}, a_{1 f}}=\rho_{a_{2 m}, a_{2 f}}$ ).

These restrictions leave us with the following 10 parameters that need to be assigned:

1. Mean value of $\log$ ability in occupation $2\left(\mu_{a_{2}}\right)$;

2. Mean value of $\log$ taste for leisure $\left(\mu_{\phi}\right)$;

3. Variance of $\log$ ability in occupation $1\left(\sigma_{a}^{2}\right)$;

4. Variance of $\log$ ability in occupation $2\left(\sigma_{a}^{2}\right)$;

5. Variance of log taste for leisure $\left(\sigma_{\phi}^{2}\right)$;

6. Correlation of abilities in occupations 1 and $2\left(\rho_{a_{1}, a_{2}}\right)$;

\footnotetext{
${ }^{24}$ Note that in our model a uniform skill gap is equivalent to uniform wage discrimination.
} 
7. Correlation of abilities among males and females within couples $\left(\rho_{a_{1 m}, a_{1 f}}\right.$ and $\rho_{a_{2 m}, a_{2 f}}$, which are assumed equal);

8. Correlation between taste for leisure of males and females within couples $\left(\rho_{\phi_{m}, \phi_{f}}\right)$;

9. Gender (uniform) gap in skills $\left(\bar{\mu}_{g}\right)$

10. Gender difference in Pareto weights (recall that $\alpha_{m}+\alpha_{f}=2$ ).

Targeted moments. Although the endogenous equilibrium outcomes of interest will be jointly determined by all of these parameters, one of the benefits of reducing the set of parameters to these ten is that each of these parameters is intuitively closely connected with a particular moment of interest. Here we list these connections in turn.

The mean value of $\log$ ability in occupation $2\left(\mu_{a_{2}}\right)$ will be closely connected with the share of male employment in occupation 1 . The mean value of the log taste for leisure $\left(\mu_{\phi}\right)$ will be closely connected with the mean level of hours worked. The variance of idiosyncratic productivities $\left(\sigma_{a 1}^{2}, \sigma_{a 2}^{2}\right)$ will be closely connected with the variance of wages (in each occupation). The correlation of abilities $\left(\rho_{a 1, a 2}\right)$ in the two occupations will influence selection of individuals into occupations by overall ability and therefore mean wage difference across occupations. $^{25}$ The variance of $\log$ taste for leisure $\left(\sigma_{\phi}^{2}\right)$ will be closely connected with the variance in hours of work. The two correlation parameters linking idiosyncratic values for spouses $\left(\rho_{a_{1 m}, a_{1 f}}=\rho_{a_{2 m}, a_{2 f}}\right.$ and $\left.\rho_{\phi_{m}, \phi_{f}}\right)$ will be closely connected to the correlations of hours and wages between spouses. The gender skill gap and the female Pareto weight will be closely connected to with the gender wage gap and with the average level of hours worked by females. With these connections in mind we adopt the following targets in our calibration procedure:

1. The share of male employment in occupation 1: 0.61 .

2. Log mean hours of work by men: 7.67 .

3. The standard deviation of log male wages in occupation 1 (NL): 0.45 .

4. The standard deviation of log male wages in occupation 2 (L): 0.46 .

5. The standard deviation of log male hours: 0.26 .

6. The mean difference in male log wages between occupations 1 and 2: 0.37.

7. The correlation of log wages within households: 0.43 .

8. The mean difference in gender (log) wages: 0.42 .

9. The correlation of log hours within households: 0.02 .

10. Log mean hours of work by women: 7.40.

\footnotetext{
${ }^{25}$ These are the standard Roy model effects that we noted in Section 3 but abstracted from.
} 
Note that moments 1 through 6 in this list only involve values for males. As a practical matter we could have targeted the aggregate moments instead of just the moments for males, and our key results are relatively unaffected. So in this sense the choice is not of first order importance. But we chose to target the male moments as a way to minimize the extent to which we were implicitly targeting moments for females that are related to the moments whose properties we were most interested in. The second and fifth entries in the above list target aggregates for men. We can expand our list to include the occupation specific levels as well. We have done this as a robustness check, and the results are reported in Appendix D. This has relatively little effect on our key results.

We explicitly target female wages and female hours. As noted above, these moments are used to identify the two other gender asymmetries in the environment, which we believe are potentially very relevant when evaluating our mechanism. Essentially, we want our model to properly capture both the incentives for females to engage in market work and the amount of market work that they choose. This desire is motivated by the possibility that market responses to asymmetric allocations of home production time are plausibly affected by asymmetries in market opportunities and preferences. ${ }^{26}$ But we have also calibrated a version of the model in which the only exogenous gender difference is in the time endowment. The results are reported in Appendix E. Naturally, this model does not match the overall gender differences in hours and wages. However, the effect of differences in the time endowment on the gender wage gap is quantitatively similar in both frameworks.

The calibration is performed by minimizing a loss function that sums the square of differences between the above listed moments in the model and in the data. Table 5 reports the calibrated parameters as well as the fit of the calibrated model to the targeted moments.

Parameter values and discussion. The model accounts well for all the targeted moments. Here we note how some of the calibrated parameters work to achieve the desired targets. The model matches the differences in male mean wages across occupations of $37 \%$ in the data. Consistent with our earlier discussion in Section 3, selection effects via a standard Roy model channel play an important role. The calibration yields a positive correlation between skills $\left(\rho_{a 1, a 2}=0.344\right)$ and a higher variance in ability 1 than ability 2 $\left(\sigma_{1}^{2}=0.315>\sigma_{2}^{2}=0.195\right)$. This leads more individuals with higher absolute advantage to choose occupation 1.

The standard deviation of male log hours in the baseline economy is 0.27 , which compares well with the 0.26 value in the data. The intra-household interactions in the model generate some dispersion in hours given dispersion in productivity within the household, but the calibration requires substantial heterogeneity in the taste for leisure: $\sigma_{\phi}^{2}=0.403$.

The baseline model economy matches both the gender gap in hours of work $(27 \%)$ and the gender gap in wages $(42 \%)$ in the data. For reasons discussed earlier, we felt it was important that the model match both of these targets, and motivated the inclusion of two additional sources of asymmetries: the skill gap and differential Pareto weights. Both of these features play an important role. Matching the gender wage gap requires a gender skill (or wage discrimination) gap of about 33\%, and matching the gender hours gap requires

\footnotetext{
${ }^{26}$ To the extent that this exogenous skill gap may also be affected by the asymmetric allocation of home production duties, our analysis will present a lower bound.
} 
Table 5: Calibration with $\theta=0.6$.

\begin{tabular}{lclcc}
\hline \hline Parameter & Value & Target & Data & Model \\
& & & & \\
\hline$\mu_{a_{2}}$ & -0.146 & $E_{m}^{N L}$ & 0.61 & 0.60 \\
$\sigma_{a_{1}}^{2}$ & 0.315 & $s d\left(\ln w_{m, N L}\right)$ & 0.45 & 0.48 \\
$\sigma_{a_{2}}^{2}$ & 0.195 & $s d\left(\ln w_{m, L}\right)$ & 0.46 & 0.43 \\
$\mu_{\phi}$ & 0.728 & $\ln \overline{h_{m}}$ & 7.67 & 7.67 \\
$\sigma_{\phi}^{2}$ & 0.403 & $s d\left(\ln h_{m}\right)$ & 0.26 & 0.27 \\
$\rho_{a_{1}, a_{2}}$ & 0.344 & $\ln \overline{w_{m, N L}}-\ln \overline{w_{m, L}}$ & 0.37 & 0.37 \\
$\rho_{a_{m}, a_{f}}$ & 0.655 & gender corr. of log wages & 0.43 & 0.43 \\
$\rho_{\phi_{m}, \phi_{f}}$ & 0.755 & gender corr. of log hours & 0.02 & 0.02 \\
$\mu_{a_{m}}-\mu_{a_{f}}$ & 0.331 & gender wage gap & 0.42 & 0.42 \\
$\alpha_{f}$ & 0.773 & $\ln \overline{h_{f}}$ & 7.40 & 7.40 \\
\hline \hline
\end{tabular}

that females have a lower Pareto weight than males $\left(\alpha_{f}=0.773<\alpha_{m}=1.227\right)$. The model naturally delivers a gender hours gap given the skill gap via intra-household substitution effects. But when one incorporates the asymmetry in home production time it turns out that the model would deliver too large of a gender hours gap. It achieves the target by valuing female leisure less than male leisure. ${ }^{27}$

The model matches the correlation of wages among spouses ( 0.43 both in the model and in the data). Intra-household interactions work to create a negative correlation via occupational choice interactions. Accordingly, the calibration requires that the correlation of skills across spouses in the baseline economy is 0.655 , higher than the correlation of wages. Similarly, the intra-household interactions work to create a negative correlation between spousal hours, so the model requires a fairly high correlation of tastes for leisure $(0.755)$ in order to match the modest positive correlation of hours of work across spouses (0.02) found in the data.

The targets that the model had a harder time fitting relate to the variation of wages. In particular, the model overstates the standard deviation of male log wages in the data (0.49 versus 0.45 ) and it implies that male log-wages vary more in occupation 1 than occupation 2 by about $7 \log$ points while in the data the standard deviation of log wages is roughly equal across occupations. 
Table 6: Baseline Economy.

Part 1: Data

Males

\begin{tabular}{lccccc} 
& Emp. share & Log mean hours & Std log hours & Log mean wages & Std log wages \\
\hline Non-Linear & 0.61 & 7.73 & 0.22 & 2.56 & 0.45 \\
Linear & 0.39 & 7.57 & 0.32 & 2.19 & 0.46 \\
Aggregate & 1.00 & 7.67 & 0.26 & 2.46 & 0.45 \\
\hline
\end{tabular}

Females

\begin{tabular}{lccccc} 
& Emp. share & Log mean hours & Std log hours & Log mean wages & Std log wages \\
\hline Non-Linear & 0.37 & 7.49 & 0.39 & 2.21 & 0.49 \\
Linear & 0.63 & 7.33 & 0.50 & 1.86 & 0.47 \\
Aggregate & 1.00 & 7.40 & 0.46 & 2.04 & 0.48 \\
\hline
\end{tabular}

Part 2: Baseline

Males

\begin{tabular}{lccccc} 
& Emp. share & Log mean hours & Std log hours & Log mean wages & Std log wages \\
\hline Non-Linear & 0.60 & 7.75 & 0.16 & 2.59 & 0.48 \\
Linear & 0.40 & 7.52 & 0.31 & 2.22 & 0.43 \\
Aggregate & 1.00 & 7.67 & 0.27 & 2.46 & 0.49 \\
\hline
\end{tabular}

Females

Emp. share Log mean hours Std log hours Log mean wages Std log wages

\begin{tabular}{llllll}
\hline Non-Linear & 0.46 & 7.57 & 0.20 & 2.23 & 0.47 \\
Linear & 0.54 & 7.22 & 0.57 & 1.85 & 0.43 \\
Aggregate & 1.00 & 7.40 & 0.49 & 2.04 & 0.48 \\
\hline \hline
\end{tabular}

\subsection{Results}

We now turn to a broader examination of the model's implications for gender differences. Table 6 shows results for a large set of moments, including many that were not targeted.

Overall, the baseline economy captures the salient qualitative patterns in the data. First, looking across occupations, the model captures the fact that occupation 1 has both higher mean hours and lower dispersion in hours than occupation 2. Moreover, this holds for both men and women separately. The model also captures the occupational wage gap, at the

\footnotetext{
${ }^{27}$ While we do not pursue it further here we think that the logic of this argument represents a novel channel for identifying individual weights in the family utility function. If one ignores home production time differences the tension does not arise, so the argument emphasizes the need to incorporate home production in such exercises.
} 
aggregate level as well as for men and women separately. Second, looking across gender, the model captures the fact that women work less hours, have a higher standard deviation of hours, and are disproportionately employed in the linear occupation. Third, looking at gender differences within occupations, the model captures the fact that in both occupations women have lower mean hours than men, a higher standard deviation of hours than men, and a lower wage.

The model also does a reasonable job of accounting for many of the quantitative differences along these dimensions. For example, in the model, the share of employment in the non-linear occupation is lower for females than for males (0.46 versus 0.60$)$. In the data this gap is 0.24 , so that the model accounts for about $60 \%$ of the observed gender gap in occupational employment shares.

The model matches almost perfectly the gender gap in hours dispersion: the standard deviations of $\log$ hours in the data are 0.46 and 0.26 for females and males respectively, versus 0.49 and 0.27 in the model. The model also does an excellent job of accounting for the magnitude of wage differences across occupations for each gender.

Of particular interest to us is the model's implications for the gender wage gap. As seen in Table 6, the baseline economy matches the gender wage of $42 \%$ in the data. The calibration achieved this with an "exogenous" skill gap component of $33 \%$, implying that the "endogenous" component of the gender wage gap is $9 \%$. Thus, the mechanisms present in our model that we sought to assess quantitatively account for about $25 \%$ of the overall gender wage gap in the data.

The model is also consistent with the fact that most of the gender wage gap is within occupations. The gender wage gap in the non-linear and linear occupations are $36 \%$ and $37 \%$ respectively, while the corresponding values in the data are $35 \%$ and $33 \%$. Hence, the gender differences in the occupational structure account for a somewhat smaller fraction of the gender wage gap in the model than in the data. This result is not surprising given that the model only accounts for $60 \%$ of the gender gap in occupational structure. ${ }^{28}$

In the next subsection we seek to provide more detail on how various model features interact to generate these differences. In particular, we will be interested in assessing the marginal contribution of the gender asymmetry in discretionary time to the gender differences just noted.

\footnotetext{
${ }^{28}$ We have also calibrated a version of our model with a non-uniform gender skill (discrimination) gap calibrated so as to match the gender wage gap in each of the two occupations. The calibrated model economy requires an 8 percentage point higher gender skill (discrimination) gap in the nonlinear occupation than in the linear occupation. Nonetheless, because in the resulting equilibrium females employed in the nonlinear (linear) occupation are positively (negatively) selected in terms of their skills, the gender wage gap in the nonlinear sector is only 2 percentage points higher than in the linear occupation, as in the data. Moreover, the employment share of females in the nonlinear occupation is now $41 \%$, as compared to $46 \%$ in the baseline economy and $37 \%$ in the data. Because of the opposing effects associated with selection, this exercise yields results that are very close to those in our benchmark model with a uniform gender skill gap.
} 


\subsection{The Role of Model Features, Selection, and Gender Differ- ences}

While the workings of our basic model are fairly intuitive, we believe it is of interest to provide some additional information about how the various aspects of the model interact and what their quantitative significance is. To do this we will deconstruct our baseline model by starting with a simple model and progressively adding in features to ultimately yield our baseline economy.

The simple economy that serves as our starting point is created by taking our baseline economy, breaking up all two member households to form single individual households, and eliminating the gender gap in discretionary time. With single individual households Pareto weights are irrelevant, so the only gender asymmetry in this economy is the uniform skill gap. We think this is an interesting starting point for the exercise.

In the second economy, we place individuals back into two member households, but at this stage we do this so as to have no assortative matching, i.e., the correlation of spousal characteristics is assumed to be zero. Additionally, in this economy we assume that Pareto weights are equal within the household. The third economy we consider will reshuffle individuals relative to the second economy so as to achieve the level of assortative matching in the baseline economy. The fourth economy adds the asymmetry in Pareto weights as in the baseline economy. And the final economy is identical except that we now introduce the asymmetry in discretionary time as in the baseline model.

We do not want to claim that the marginal effects identified in this sequencing are robust to the order of sequencing. Rather, we feel that an exercise like this yields useful insight into the interactions implicit in the results obtained in the baseline model. Nonetheless, we are particularly interested in the results of the last step in which we introduce gender asymmetries in time endowments. This experiment helps us assess how the unequal division of home production activities matters in accounting for gender asymmetries in labor market outcomes in our calibrated model economy. The assessment of these effects is a key objective of our paper.

\subsubsection{Starting Point: Single Individual Households}

Table 7 shows that in this economy with single individual households there are no gender differences in hours of work nor in the occupational structure. Although there is a gender wage gap, it is exactly equal to the gender skill gap. Our assumption of preferences with utility from consumption equal to $\log c$ plays a role in this outcome, since it implies that desired hours of work are invariant to the level of wages. The key point is that the model features in this economy create no amplification of the exogenous skill gap and create no asymmetries in terms of hours worked or occupational choice.

\subsubsection{The Role of Couples with Random Matching}

We now assume that individuals are matched to form two person households but that the matching is random from the perspective of individual characteristics. This economy introduces all of the intra-household effects that we have previously highlighted. Recall that in this economy there is no asymmetry in discretionary time endowments. 
The second column in Table 7 illustrates how family interactions serve to propagate the effects of a uniform skill gap. A key direct effect is to create a gender gap in hours of work. Relative to the single individual household economy, this gap increases from 0 to 14 percent. Even without a skill gap, family interactions will increase the dispersion in work hours as families take advantage of heterogeneity in productivities among their members. Additionally, a gender gap in hours of work naturally leads to a gender gap in the dispersion of work hours, through the effect noted earlier in Figure 11. As a result, whereas the standard deviation of hours was 0.19 for both genders in the singles economy, this value increases to 0.40 for males and to 0.61 for females in this economy.

The drop in desired hours of work by gender also generates effects on occupational choice. As a result, we now have a gender gap in occupational choice equal to 7 percentage points. ${ }^{29}$

A particular concern for us is how various features interact to produce gender wage gaps. In this economy the gender wage gap is $35.4 \%$, indicating some amplification of the exogenous skill gap. Notice that this effect is of opposite signs across the two occupations. While the gender wage gap increases from $33 \%$ to $34 \%$ in the linear sector, it decreases from $33 \%$ to $31 \%$ in the non-linear sector.

This asymmetry reflects the effects of selection. The lower hours of work of women relative to men creates a disincentive for choosing the non-linear occupation, causing women to move from the non-linear to the linear sector. As a result, the women remaining in the non-linear occupation are more positively selected in terms of the skill ratio $\frac{a_{1}}{a_{2}}$ than men the mean value of $\frac{a_{1}}{a_{2}}$ is about $4.8 \%$ higher for women than men (see Table 8). Moreover, women in the non-linear occupation are more negatively selected in terms of taste for leisure than men - the mean value of $\ln (\phi)$ is about $6.8 \%$ lower for women than men, partly undoing the negative income effect from their spouses. The selection effects in turn amplify the gender wage gap in the linear occupation because the women that are discouraged from working in the non-linear occupation have lower comparative advantage in the linear occupation. A key message from this economy is that part of the endogenous gender wage gap in our baseline model reflects the interaction of our model features with the exogenous skill gap.

\subsubsection{Adding Assortative Matching}

Moving to the case with correlated skills and preferences across household members creates two sets of effects. First, more similarity among household members makes their choices more substitutable. Given the uniform gender skill gap, this tends to increase gender differences. Consistent with this, we see that the gender wage gap, the gender hours gap and the gender occupational choice gap all increase. Second, the correlation also affects intra-household wealth effects. A key dimension along which we see this increased substitutability is that average hours decrease for those in the linear sector and increase for those in the non-linear sector. An additional effect is that when skills are correlated across household members the distribution of male wealth effects on female labor supply is altered. The net effect is a small increase in hours even for women and a small increase in the fraction of women who work in the non-linear occupation. In sum, through family interactions, assortative matching propagates the effect of gender asymmetries on labor market outcomes. Intuitively, the

\footnotetext{
${ }^{29}$ It is interesting to note that in this economy we also have fewer males in the non-linear occupation relative to the singles economy. This reflects the income effect from spousal labor supply.
} 
greater the extent of assortative matching, the more substitutable are the hours of the two spouses, leading to larger responses to any exogenous difference across genders.

\subsubsection{Adding Heterogeneous Pareto Weights}

We now add the heterogeneity in Pareto weights from our baseline economy. Intuitively, decreasing the relative weight on the utility of females implies less weight on their leisure, thereby leading to a reallocation of working time from men to women. The magnitude of this effect is significant, reducing the gender gap in hours of work from $16 \%$ to $-6 \%$ and reducing the gender gap in the share of employment in the non-linear occupation from 9 percentage points to -3 percentage points. These effects underscores that in our extended Roy model taste for leisure matters importantly for the sorting of workers. The effect on the gender wage gap is significant, reducing it from $38 \%$ to $31 \%$. Interestingly, contrary to our baseline economy, in both sectors the gender wage gap is smaller than the gender skill gap. Table 8 shows that now women in the non-linear occupation are worse selected than males since gender differences in mean skills are higher than the exogenous skill differences (34.2\% vs $33 \%)$. Conversely, women in the linear occupation are better selected than males (the gender skill difference in this occupation is now $32.4 \%$, which is smaller than the skill difference on the overall population of 33\%).

In terms of magnitudes, note that the mean hours of work for females in this economy is very similar to what we found for the singles economy. That is, the intra-family substitution effects that lowered female hours of work are largely offset by the differences in Pareto weights. The same is true for the gender wage gap.

\subsubsection{Adding Gender Differences in Time Endowments}

The final feature to add back is the gender difference in time endowments. The direct effect is for women to decrease their desired hours of work, which in turn interacts with occupational choice and male labor supply. While the nature of the effects is familiar given the previous analysis, the size of the effects is noteworthy. Female hours drop by $28 \%$ while male hours increase by $5 \%$, increasing the gender gap in hours from $-6 \%$ to $27 \%$. The gender gap in occupational choice increases from -3 percentage points to 14 percentage points.

The gender difference in time endowments also has a large effect on wages: The gender wage gap increases from $31 \%$ to $42 \%$, with the wage gap in each sector increasing by about 5 percentage points. Behind these effects are the same selection effects discussed previously: The large decrease in desired hours of work for women leads to a large decrease in hours in the non-linear occupation. The women remaining in the non-linear (moving to the linear) occupation are then more positively (negatively) selected in terms of their skills. Table 8 shows that the magnitude of this effect is large: The gender difference in skills in the nonlinear occupation is reduced by about 10 percentage points (the gender difference in mean skill in the linear occupation is increased by 6 percentage points). Since the hours gap in the non-linear occupation increases from $-5 \%$ to $18 \%$ and this effect outweighs the selection effect on wages, the gender wage gap in the non-linear sector rises from 31 to $36 \%$. 


\subsubsection{Summary}

The goal of this section was to provide some insight into how the various features of the model interact and to assess how gender differences in time endowments matter for asymmetric labor market outcomes. There are three main messages that we want the reader to take away from this deconstruction exercise. First, family interactions play a very important role in propagating underlying sources of gender asymmetries. Second, the propagation via family interactions is influenced in a very significant way by the extent of assortative matching. Third, the endogenous component of the gender wage gap in our baseline model reflects the propagation of three underlying sources of gender asymmetries: the uniform skill gap, the discretionary time gap and the Pareto weight gap. While each is significant, the effects of the $10 \%$ gender gap in discretionary time alone is large: it increases the gender wage gap by 11, the hours gap by 33, and the occupational choice gap by 17 percentage points, respectively.

Table 7: The Role of Model Features.

\begin{tabular}{lccccc}
\hline \hline & $\begin{array}{c}\text { Everyone } \\
\text { Single }\end{array}$ & $\begin{array}{c}\text { iid } \\
\text { Matching }\end{array}$ & $\begin{array}{c}\text { Assortative } \\
\text { Matching }\end{array}$ & $\begin{array}{c}\text { Pareto } \\
\text { Weights }\end{array}$ & $\begin{array}{c}\text { Time } \\
\text { Endowments }\end{array}$ \\
\hline Wage Gap (\%) & 33.0 & 35.4 & 38.1 & 31.0 & 42.0 \\
Log Hours Males & 7.66 & 7.68 & 7.71 & 7.62 & 7.67 \\
Log Hours Females & 7.66 & 7.54 & 7.55 & 7.68 & 7.40 \\
Hours Gap (\%) & 0 & 14 & 16 & -6 & 27 \\
Std Hours Males & 0.19 & 0.40 & 0.25 & 0.34 & 0.26 \\
Std Hours Females & 0.19 & 0.61 & 0.45 & 0.32 & 0.49 \\
Share Emp. NL Males & 0.62 & 0.59 & 0.62 & 0.57 & 0.60 \\
Share Emp. NL Females & 0.62 & 0.52 & 0.53 & 0.60 & 0.46 \\
Log Wage Males & 2.45 & 2.48 & 2.47 & 2.44 & 2.46 \\
Log Wage Females & 2.12 & 2.13 & 2.09 & 2.14 & 2.04 \\
\hline Non-Linear Occupation & & & & & \\
Log Wages Males & 2.55 & 2.63 & 2.60 & 2.59 & 2.58 \\
Log Wages Females & 2.22 & 2.32 & 2.26 & 2.28 & 2.23 \\
Wage Gap \% & 33.1 & 31.1 & 36.7 & 31.0 & 36.3 \\
Log Hours Males & 7.73 & 7.80 & 7.78 & 7.72 & 7.75 \\
Log Hours Females & 7.73 & 7.74 & 7.69 & 7.77 & 7.57 \\
Hours Gap \% & 0 & 6 & 19 & -5 & 18 \\
\hline Linear Occupation & \multirow{2}{*}{2.24} & 2.20 & 2.23 & 2.21 & 2.22 \\
Log Wages Males & 1.91 & 1.86 & 2.26 & 1.88 & 1.85 \\
Log Wages Females & 33.1 & 34.9 & 33.9 & 32.5 & 37.8 \\
Wage Gap \% & 7.55 & 7.48 & 7.57 & 7.46 & 7.52 \\
Log Hours Males & 7.55 & 7.27 & 7.37 & 7.52 & 7.22 \\
Log Hours Females & 0 & 21 & 20 & -6 & 30 \\
Hours Gap \% & & & & & \\
\hline \hline
\end{tabular}


Table 8: Model Features and Selection.

\begin{tabular}{|c|c|c|c|c|c|}
\hline & $\begin{array}{l}\text { Everyone } \\
\text { Single }\end{array}$ & $\begin{array}{c}\text { iid } \\
\text { Matching }\end{array}$ & $\begin{array}{l}\text { Assortative } \\
\text { Matching }\end{array}$ & $\begin{array}{l}\text { Pareto } \\
\text { Weights }\end{array}$ & $\begin{array}{c}\text { Time } \\
\text { Endowments }\end{array}$ \\
\hline \multicolumn{6}{|l|}{ Mean $(\log )$ skill in NL } \\
\hline females & 4.52 & 4.61 & 4.58 & 4.54 & 4.62 \\
\hline gender diff in logs & 0.33 & 0.27 & 0.28 & 0.34 & 0.24 \\
\hline $\begin{array}{l}\text { Mean }(\log ) \text { skill in L } \\
\text { males }\end{array}$ & 4.59 & 4.55 & 4.57 & 4.55 & 4.57 \\
\hline females & 4.26 & 4.20 & 4.20 & 4.23 & 4.19 \\
\hline gender diff in logs & 0.33 & 0.35 & 0.36 & 0.32 & 0.38 \\
\hline \multicolumn{6}{|l|}{ Mean $(\log ) \phi$ in NL } \\
\hline females & 24.65 & 24.55 & 24.57 & 24.62 & 24.53 \\
\hline gender diff in logs & 0.00 & 0.07 & 0.076 & -0.01 & 0.11 \\
\hline \multicolumn{5}{|l|}{ Mean $(\log ) \phi$ in $\mathrm{L}$} & 24.85 \\
\hline females & 24.83 & 24.82 & 24.85 & 24.85 & 24.84 \\
\hline gender diff in logs & 0.00 & 0.03 & -0.009 & 0.01 & 0.01 \\
\hline \multicolumn{6}{|l|}{ Mean $(\log ) \frac{a_{N L}}{a_{L}}$ in NL } \\
\hline males & 0.55 & 0.55 & 0.54 & 0.56 & 0.55 \\
\hline females & 0.55 & 0.60 & 0.58 & 0.55 & 0.63 \\
\hline gender diff in logs & 0.00 & -0.048 & -0.046 & 0.02 & -0.08 \\
\hline \multicolumn{5}{|l|}{ Mean $(\log ) \frac{a_{L}}{a_{N L}}$ in L } & 0.35 \\
\hline female & 0.38 & 0.26 & 0.27 & 0.34 & 0.21 \\
\hline gender diff in logs & 0.00 & 0.07 & 0.10 & -0.02 & 0.14 \\
\hline \multicolumn{5}{|l|}{ Employment share NL } & 0.60 \\
\hline female & 0.62 & 0.52 & 0.53 & 0.60 & 0.46 \\
\hline gender diff in logs & 0.00 & 0.07 & 0.09 & -0.02 & 0.14 \\
\hline
\end{tabular}

\subsubsection{Sensitivity Analysis}

We previously noted how a slight variation in the choice of moments for the calibration exercise has very little effect on our results. Specifically, in Appendix D we show that matching a larger set of moments for males does not impact our main findings in a significant way.

Perhaps most importantly, given the lack of a definitive estimate for $\theta$ it is of interest to know how our results are affected by variation in this value. In Appendix F we report detailed 
results for alternative calibrations of the model economy $(\theta=0.4, \theta=0.8$, and $\theta=1.0)$. Full results are provided there but perhaps key results to focus on is the quantitative assessment of gender differences in discretionary time on various gender gaps. These results are reported in Table 9. In the baseline model the gender difference in discretionary time implied an increase in the gender wage gap of 11, the hours gap by 33, and the occupational choice gap by 17 percentage points, respectively. In the economy with $\theta=0.4$, these effects are smaller but still significant: the gender wage gap increases by 7 , the hours gap by 30 , and the occupational choice gap by 11 percentage points. In the economy with $\theta=1$, the effects become much larger with an increase in the gender, hours and occupational gaps of 24, 43, and 30 percentage points, respectively.

Table 9: Sensitivity: Shutting Down Time Endowment Differences.

\begin{tabular}{lrrrr}
\hline \hline & & & & \\
& & & & \\
& & & & \\
& & & & \\
\hline & & & & \\
Percentage (or percentage point) change in: & & & \\
Wage Gap & -7.1 & -11.5 & -17 & -23.7 \\
Log Hours Males & -4.2 & -5.3 & -7 & -9.6 \\
Log Hours Females & 25.6 & 27.7 & 30.3 & 33.6 \\
Hours Gap & -30 & -33 & -37.3 & -43.2 \\
Std Hours Males & 5 & 7.2 & 10 & 13.8 \\
Std Hours Females & -13.6 & -17.3 & -18.8 & -22 \\
Share Emp. NL Males & $-1-6$ & -3.2 & -5.9 & -8.4 \\
Share Emp. NL Females & 9.6 & 14.1 & 18.7 & 24 \\
Log Wage Males & -1 & -1.9 & -3.2 & -5.3 \\
Log Wage Females & 6.1 & 9.6 & 13.7 & 18.4 \\
\hline Non-Linear Occupation & & & & \\
Log Wages Males & -0.3 & -0.4 & -0.8 & -1 \\
Log Wages Females & 3.3 & 5 & 7.1 & 9.4 \\
Wage Gap & -3.6 & -5.4 & -7.9 & -10.4 \\
Log Hours Males & -3.3 & -3.5 & -4.1 & -4.6 \\
Log Hours Females & 20.7 & 20 & 20 & 20.3 \\
Hours Gap & -24 & -23.5 & -24.1 & -24.9 \\
\hline Linear Occupation & & & & \\
Log Wages Males & -0.8 & -1.5 & -2.8 & -4.9 \\
Log Wages Females & 2.2 & 3.8 & 6.2 & 9.5 \\
Wage Gap & -2.9 & -5.3 & -9 & -14.4 \\
Log Hours Males & -4.8 & -6.3 & -8.4 & -11.2 \\
Log Hours Females & 28 & 29.6 & 31.2 & 33.2 \\
Hours Gap & -32.8 & -35.9 & -39.6 & -44.4 \\
\hline \hline & & & & \\
\hline
\end{tabular}




\section{Gender Inequality and the Misallocation of Talent}

A recent paper by Hsieh et al. (2016) argues that the US economy has had a significant degree of misallocation of talent across occupations along the dimensions of race and gender, and that this misallocation has quantitatively important effects on aggregate output. Their analysis was silent on the issue of what underlying factors were driving the observed misallocation. Our analysis has studied one particular driving force: the uneven division of nonmarket responsibilities. In this section we evaluate the aggregate implications of this source of misallocation.

Our analysis has assumed an exogenous gender gap in skills, or equivalently, in gender wage discrimination. To the extent that part or all of this differential reflects some form of discrimination there is an additional source of misallocation that we are not considering. Moreover, even if the skill gap truly reflects only productivity differences, it is plausible that the exogenous gender gap in discretionary time might induce some part of the difference in skills. In view of this we interpret our results as a somewhat conservative lower bound.

We assess the productivity and welfare effects of the uneven division of household hours as follows. We take the gender differences in skills as given and interpret them as true productivity differences. We then consider the choices of a Social Planner endowed with a utilitarian welfare function over individual utilities. Implicitly, the planner is effectively assigning equal weights to the utility of each of its two household members. Additionally, rather than taking as given that the uneven distribution of home tasks leaves women with 500 fewer hours of discretionary, for each household the Planner optimally assigns the 500 hours of home production tasks to one of the members. Implicit in our exercise is the assumption that there is no heterogeneity in home productivity across family members. While this assumption is relevant for evaluating welfare gains, it does not influence the calculations for changes in labor productivity in the market sector.

One might conjecture that with symmetric Pareto weights it would be optimal to divide home activities equally among household members. It turns out that this is not the case. The reason for this is that the non-linear mapping of hours to labor services in the nonlinear occupation creates a non-convexity and thus generates a motive for specialization. It turns out that it is preferable in terms of aggregate welfare to arbitrarily assign all of the home production activities to one of the two genders, rather than dividing the duties equally between the two of them. Given the heterogeneity within households, one can in principle create welfare gains by allowing each household to determine which individual should specialize in home production. ${ }^{30}$

We find that the Social Planner chooses to allocate the 500 hours of home production time to males in roughly $23 \%$ of households. In the absence of gender differences in skills, this fraction would be $50 \%$ given that we have imposed symmetry on the distribution of characteristics for males and females. Relative to our baseline economy, this produces an

\footnotetext{
${ }^{30}$ If the two household members have sufficiently different tastes for leisure it is possible for the optimal allocation to involve both individuals doing some home production work. In such a case the low taste for leisure individual will work in the market and at home and the high taste for leisure individual will only work at home. For reasons of tractability we do not allow the Social Planner to choose allocations of this form, and so the gains that we compute represent a lower bound on the effects of misallocation. Having pointed this out, this scenario is quite rare is so is unlikely to have a large impact on our results.
} 
important reallocation of hours worked across men and women: hours worked by women decrease by 8.9 percent, whereas men increase hours by 0.4 percent. The direction of these changes is perhaps not surprising given the Social Planner is using equal Pareto weights. But the net effect is a decrease in aggregate hours worked of roughly 3.5 percent. This reallocation implies an aggregate welfare gain in terms of consumption equivalents of $6.9 \%{ }^{31}$

Productivity is key to understanding these welfare effects. We find an increase in aggregate labor productivity (total output divided by total hours of work) of $5.4 \%$. This is achieved by more effectively allocating home production duties. Note that the average gain in welfare measured in units of consumption is greater than the increase in productivity. This indicates both that average leisure is increasing and that leisure is allocated more effectively across individuals.

It is also of interest to note how the productivity gains vary by occupation and gender. We find that the productivity gains are much higher for females than males $(6.4 \%$ versus $3.6 \%$ ). The productivity gains are particularly large among females and males working in the non-linear occupation: their output per hour rises by $9.3 \%$ and $4.7 \%$. In the linear occupation, productivity gains are much lower ( $0.9 \%$ for females and $0.5 \%$ for males).

Obviously, the non-linear occupation is crucial for the large impact of gender equality on welfare and labor productivity. When the non-linear occupation is shut down in the baseline economy, the mean welfare gain from gender equalization drops from $6.9 \%$ to $3.5 \%$. Moreover, the increase in output per hour decreases by more than half $(2.2 \%$ versus $5.4 \%$ in the baseline economy).

Finally, Table 10 shows how the misallocation results vary across economies with different values of $\theta$. Recall that in the baseline economy the gains of eliminating gender inequality in welfare (consumption compensation) and output per hour were $6.9 \%$ and $5.4 \%$. These results change monotonically with $\theta$. When $\theta$ changes from 0.4 to 1.0 , the welfare gain increases from $5.4 \%$ to $11.3 \%$ and the gain in output per hour rises from $4.1 \%$ to $9.7 \%$.

Table 10: Sensitivity: Misallocation across Economies.

\begin{tabular}{lrrrr}
\hline \hline & $\theta=0.4$ & $\theta=0.6$ & $\theta=0.8$ & $\theta=1.0$ \\
& & & & \\
\hline & & & & \\
Percentage change of: & 5.4 & 6.9 & 8.8 & 11.3 \\
Aggregate Welfare & 1.5 & 1.7 & 1.9 & 2.0 \\
Aggregate Output & 4.1 & 5.4 & 7.2 & 9.7 \\
Aggregate Output per Hour & & & & \\
\hline \hline
\end{tabular}

\footnotetext{
${ }^{31}$ To evaluate the welfare gain we compare the utility of the Planner in the baseline economy with the one obtained by solving the Social Planner's Problem. Consumption equivalents are computed in terms of the consumption increase in the baseline economy needed to attain the utility in the Planner's problem.
} 


\section{Conclusion}

In this paper we have documented a robust negative correlation between mean individual hours of work and the dispersion of individual hours of work across occupations in the US. We show that this pattern can be captured both qualitatively and quantitatively in a simple Roy model of occupational choice extended to include a labor-leisure tradeoff and a non-linear hours-earnings profile that is heterogeneous across sectors.

We then extend this framework to a multi-member household setting in which women have roughly ten percent lower discretionary time than men, consistent with evidence from time use surveys showing that women spend more time in home production than men. Although relatively simple, our model captures a rich set of tradeoffs in terms of individual and family choices. Our main message is that developing a theory of time allocation and occupational choice is important for understanding the forces that shape gender differences in labor market outcomes. We find that household interactions amplify the consequences of the gender differences in home production, leading to substantial gender differences in labor market outcomes: A 10 percent reduction in the discretionary time of women, reduces the share of women employed in the nonlinear occupation by 14 percentage points and increases the gender wage gap by 11 percentage points. The uneven distribution of nonmarket time provides an explanation for the misallocation of talent discussed in Hsieh et al. (2016)). We evaluate the size of this misallocation assuming no gender differential in home sector productivity and find it to be large. The aggregate welfare cost is $6.9 \%$ of consumption and the cost in terms of output per hour of work is $5.4 \%$.

We believe it will be of interest to extend our framework to a life cycle setting to shed additional light on the non-linearities that differ across occupations, and that it will be of interest to expand the empirical analysis to other countries. Finally, recent papers study how changes in the occupational structure over time have lead to an increase in wage inequality and job polarization (see Kambourov and Manovskii (2009a) and Autor and Dorn (2013)). Our paper suggests that these time trends may have also mattered for changes in hours of work and for gender differences in labor market outcomes - issues that are left for future research.

\section{References}

Aaronson, D. and E. French, "The Effect of Part Time Work on Wages: Evidence from Social Security Rules," Journal of Labor Economics 22 (2004), 329-352.

Acemoglu, D. And D. Autor, "Skills, Tasks and Technologies: Implications for Employment and Earnings," in O. Ashenfelter and D. Card, eds., Handbook of Labor Economicsvolume 4B (Amsterdam: Elsevier, 2011), 1043-1171.

Adda, J., C. Dustmann And K. Stevens, "The Career Cost of Children," Journal of Political Economy 125 (2017), 293-337. 
Albrecht, J., A. Bjorklund and S. Vroman, "Is There a Glass Ceiling in Sweden?," Journal of Labor Economics 21 (2003), 145-177.

Autor, D. And D. Dorn, "The Growth of Low-Skill Service Jobs and the Polarization of the US Labor Market," American Economic Review 103 (2013), 1553-1597.

Becker, G., "Human Capital and the Personal Distribution of Income: An Analytical Approacht," Manuscript, University of Michigan, 1967.

Ben-Porath, Y., "The Production of Human Capital and the Life Cycle of Earnings," Journal of Political Economy 75 (1967), 352-365.

Bertrand, M., C. Goldin And L. Katz, "Dynamics of the Gender Gap for Young Professionals in the Financial and Corporate Sectors," American Economic Journal: Applied Economics 2 (2010), 228-255.

Blau, F. And L. KAhn, "Gender differences in Pay," Journal of Economic Perspectives 14 (2000), 75-99.

, "The Gender Wage Gap: Extent, Trends and Extrapolations," Working paper \#21913, NBER, 2016.

Buser, T., M. Niederle And H. Oosterbeek, "Gender, Competitiveness, and Career Choices," Quarterly Journal of Economics 129 (2014), 1409-1447.

Chiappori, P.-A., "Collective Labor Supply and Welfare," Journal of Political Economy 100 (1992), 437-467.

Chiappori, P.-A. And O. Donni, "Nonunitary Models of Household Behavior: A Survey of the Literature," in A. Molina, ed., Household Economic Behaviors (Springer, 2011), $1-40$.

Cogan, J., "Fixed Costs and Labor Supply," Econometrica 49 (1981), 945-963.

Cortés, P. And J. PAn, "Occupation and Gender," Discussion Paper 10672, IZA Institute of Labor Economics, 2017a.

"When Time Binds: Returns to Working Long Hours and the Gender Wage Gap among the Highly Skilled," Mimeo, Boston University, 2017b.

Duernecker, G. And B. Herrendorf, "Structural Transformation of Occupation Employment," Mimeo, Arizona State University, 2016.

Dustmann, C. And C. Meghir, "Wages, Experience and Seniority," Review of Economic Studies 72 (2005), 77-108.

Eckstein, Z., M. P. Keane And O. Lifshitz, "Sources of Change in the Life-Cycle Decisions of American Men and Women: 1962-2014," CEPR Discussion Paper Series, Labour Economics 11393 (2016), 1-55. 
Erosa, A., L. Fuster And G. Kambourov, "Towards a Micro-Founded Theory of Aggregate Labor Supply," Review of Economic Studies 83 (2016a), 1001-1039.

Erosa, A., L. Fuster and D. Restuccia, "A Quantitative Theory of the Gender Gap in Wages," European Economic Review 85 (2016b), 165-187.

French, E., "The Effects of Health, Wealth, and Wages on Labor Supply and Retirement Behavior," Review of Economic Studies 72 (2005), 395-427.

Gicheva, D., "Working Long Hours and Early Career Outcomes in the High-End Labor Market," Journal of Labor Economics 31 (2013), 785-824.

Goldin, C., "A Grand Gender Convergence: Its Last Chapter," American Economic Review 104 (2014), 1091-1119.

Grenwood, J., N. Guner, G. Kocharkov and C. Santos, "Technology and the Changing Family: A Unified Model of Marriage, Divorce, Educational Attainment, and Married Female Labor-Force Participation," American Economic Journal: Macroeconomics 8 (2016), 1-41.

Gronau, R., "Sex-Related Wage Differentials and Women's Interrupted Careers-the Chicken or the Egg," Journal of Labor Economics 6 (1988), 277-301.

Guner, N., R. Kaygusuz and G. Ventura, "Taxation and Household Labor Supply," Review of Economic Studies 79 (2012), 1113-1149.

Gustman, A. L. And T. L. Steinmeier, "The Effect of Partial Retirement on the Wage Profiles of Older Workers," Industrial Relations 24 (1985), 257-265.

, “A Structural Retirement Model," Econometrica 54 (1986), 555-584.

Heathcote, J., K. Storesletten and G. L. Violante, "The Macroeconomics Implications of Rising Wage Inequality in the United States," Journal of Political Economy 118 (2010), 681-722.

—-, "Consumption and Labor Supply with Partial Insurance: An Analytical Framework," American Economic Review 104 (2014), 2075-2126.

Hsieh, C.-T., E. Hurst, C. I. Jones And P. J. Klenow, "The Allocation of Talent and U.S. Economic Growth," Mimeo, 2016.

Imai, S. And M. P. Keane, "Intertemporal Labor Supply and Human Capital Accumulation," International Economic Review 45 (2004), 601-641.

Jones, L. E., R. E. Manuelli and E. R. McGrattan, "Why are Married Women Working so Much?," Journal of Demographic Economics 81 (2015), 75-114.

Kambourov, G. And I. Manovskit, "Occupational Mobility and Wage Inequlality," Review of Economic Studies 76 (2009a), 731-759. 
, "Occupational Specificity of Human Capital," International Economic Review 50 (2009b), 63-115.

Keane, M. P. And K. I. Wolpin, "The Effect of Parental Transfers and Borrowing Constraints on Educational Attainment," International Economic Review 42 (2001), 10511103.

Knowles, J., "Birth Control and the Rise in Female LFP: What Can We Learn from Women's Occupational Choices?," Mimeo, 2007.

, "Why are Married Men Working so Much?," Review of Economic Studies 80 (2013), 1055-1085.

Mincer, J. And S. Polacheck, "Family Investments in Human Capital: Earnings of Women," Journal of Political Economy 82 (1974), S76-S108.

Moffitт, R., "The Estimation of a Joint Wage-Hours Labor Supply Model," Journal of Labor Economics 2 (1984), 550-566.

Olivetti, C., "Changes in Women's Hours of Market Work: The Role of Returns to Experience," Review of Economic Dynamics 9 (2006), 557-587.

Prescott, E. C., R. Rogerson and J. Wallenius, "Lifetime Aggregate Labor Supply with Endogenous Workweek Length," Review of Economic Dynamics 12 (2009), 23-36.

Rosen, S., "The Supply of Work Schedules and Employment," in Work Time and Employment (Washington, DC: National Commission for Manpower Policy, 1978).

Roy, A. D., "Some Thoughts on the Distribution of Earnings," Oxford Economic Papers 3 (1951), 135-146.

Sullivan, P., "Empirical Evidence on Occupation and Industry Specific Human Capital," Labour Economics 17 (2010), 567-580.

Wasserman, M., "Hours Constraints, Occupational Choice, and Gender: Evidence from Medical Residents," Mimeo, 2017.

Weiss, Y. And R. Gronau, "Expected Interruptions in Labour Force Participation and Sex-Related Differentials in earnings Growth," The Review of Economic Studies 48 (1981), 607-619.

Zangelidis, A., "Occupational and Industry Specificity of Human Capital in the British Labour Market," Scottish Journal of Political Economy 55 (2008), 420-443. 


\section{A Data Description}

Our analysis is mostly based on the IPUMS-CPS files from the 1976-2010 Current Population Survey $(\mathrm{CPS}) \cdot{ }^{32}$

Annual hours and hourly wages. Total annual hours worked last year are constructed using the variables (i) weeks worked last year (WKSWORK1) and (ii) usual hours worked per week last year (UHRSWORK). Hourly wages last year are constructed using the variables (i) wage and salary income for the previous calendar year (INCWAGE) and (ii) total hours worked last year constructed above. Real hourly wages are obtained using the CPI index(=100 in 1982/84).

Consistent 1976-2010 occupational classification. The occupational classification has changed four times over the period 1976-2010. ${ }^{33}$ We use the occupational classification provided in Autor and Dorn (2013) to construct consistent occupational codes for the $1976-2010$ period. $^{34}$

\section{A.1 Obtaining the Empirical Facts in Section 2}

\section{Sample restrictions.}

- Age. 16-64.

- One Employer per Year. Some individuals might have worked in multiple occupations during the survey year. To address this, for each survey year, we focus on individuals who report having had a single employer (NUMEMPS variable). This eliminates roughly $15 \%$ of the sample observations. ${ }^{35}$

- Time Period. Our benchmark results use the pooled data from 1986-1995. In some of the analysis we also use seven 5-year periods: (1) 1976-1980; (2) 1981-1985; (3) 1986-1990; (4) 1991-1995; (5) 1996-2000; (6) 2001-2005; (7) 2006-2010.

- Number of Observations in an Occupation. The grouping of observations is important to ensure a sufficient number of observations in each occupation in order to get reliable measures of the standard deviation of hours and wages. For each time period of interest - e.g., 1976-1980 - all annual observations during that period for a particular occupation $j$ are grouped together, and the mean and the dispersion in hours and wages in occupation $j$ are computed on that sample. For each of these cases, the usual restriction is at least 30 observations in an occupation in a given time period. In some instances, or as a sensitivity analysis, we use the restriction of 60 (or 100) observations in an occupation in a given time period. When the analysis is performed for different groups - e.g., men and women - these restrictions are applied to each of the groups. The restriction of at least 30 observations in an occupation drops $4 \%$ of the occupations for men and $23 \%$ of the occupations for women in the benchmark 1986-1995 time period.

\section{A.2 Obtaining the Moments (Targets) for the Simple Benchmark Model in Section 3}

\section{Sample restrictions.}

- Age. 22-64. The multi-member household model will focus on married individuals between the age of 22 and 64 . For comparability, we impose the same age restriction in the simple benchmark model.

\footnotetext{
${ }^{32}$ The data and a detailed description can be found at http://cps.ipums.org/cps/.

${ }^{33}$ Specifically, the 1970 census classification scheme is used 1971-1982, the 1980 census classification scheme is used for 1983-1991, the 1990 census classification scheme is used for 1992-2002, and the 2000 census classification scheme is used for 2003-2010.

${ }^{34}$ The consistent occupational classification is listed in Appendix G.

${ }^{35}$ The results on the full sample of individuals, however, are quantitatively very similar and are available upon request.
} 
- Time Period. 1986-1995.

- Annual Hours. Drop observations with annual hours of less than 40 (bottom 0.5\%) or more than 4500 (top $0.5 \%$ ).

- Real Hourly Wages. Drop observations with a real hourly wage of less than 0.2 (bottom 0.1\%) or more than 200 (top $0.1 \%$ ) .

- Number of Observations in an Occupation. Use observations from occupations with at least 30 observations.

Aggregate moments. We compute log mean hours, log mean wages, the standard deviation of log hours, and the standard deviation of log wages in each occupation, using person-level weights in the analysis. Then, we report the averages of these moments, using the relative share of each occupation.

Moments for the linear and nonlinear sectors. We compute mean hours in each occupation, using person-level weights, rank all occupations by their level of mean hours, and separate them into two groups that are equal in size, based on person-level weights (using actual number of individuals, instead of person-level weights, does not change the results). We then compute log mean hours, log mean wages, the standard deviation of log hours, and the standard deviation of log wages in each occupation, using personlevel weights in the analysis. Finally, for each of the two sectors, we report the averages of these moments, using the relative share of each occupation in that sector.

Lifetime corrections for the moments. The moments computed from the IPUMS-CPS files are cross-sectional. We use the longitudinal aspect of the Panel Study of Income Dynamics (PSID) to analyze the extent to which the lifetime mean and dispersion in hours and wages differ from the observed cross-sectional mean and dispersion. We impose the following restriction on the PSID: (i) time period 1985-1996, (ii) age 22-64, (iii) married individuals, (iv) positive hours worked, and (v) individuals with positive hours worked in at least five years during that period. First, we compute the mean of hours worked and the standard deviation of $\log$ hours. Second, for each individual in the sample, we compute the mean of hours worked (and refer to it as lifetime hours), and then report the mean lifetime hours and the standard deviation of log lifetime hours. In terms of mean hours, the cross-sectional and the lifetime means are the same. In terms of the dispersion in hours, however, the dispersion in lifetime hours is systematically around two-thirds of the dispersion in cross-sectional hours. Erosa et al. (2016a) report similar findings. These patterns are robust and broadly hold for (i) men and women, (ii) different age groups, (iii) different education groups, (iv) the linear sector and the nonlinear sector of occupations. As a result, in all of the computed moments, we adjust the dispersion in hours worked by a factor of two-thirds.

We repeat the same analysis for hourly wages, instead of hours worked and find that the dispersion in lifetime hourly wages is around $10 \%$ lower than the dispersion in cross-sectional hourly wages. As a result, in all of the computed moments, we adjust the dispersion in hourly wages by a factor of nine-tenths.

\section{A.3 Obtaining the Moments (Targets) for the Multi-Member House- hold Model in Section 4}

Sample restrictions.

- Age. 22-64.

- Time Period. 1986-1995.

- Marital Status. The analysis is restricted to married (MARST variable) individuals (married, spouse present; or married, spouse absent).

- Annual Hours. Drop observations with annual hours of less than 40 or more than 4500.

- Real Hourly Wages. Drop observations with a real hourly wage of less than 0.2 or more than 200.

- Number of Observations in an Occupation. Use observations from occupations with at least 30 observations. 
Aggregate moments. The aggregate moments are computed separately for men and women. We compute log mean hours, log mean wages, the standard deviation of log hours, and the standard deviation of log wages for men and women in each occupation, using person-level weights in the analysis. Then, we report the averages of these moments for men and women across all occupations, using the relative share of men or women in each occupation.

Moments for the linear and nonlinear sectors. We compute mean hours for men in each occupation, using person-level weights, rank all occupations by the level of mean hours of men, and separate them into two groups that are equal in size (men plus women), based on person-level weights (using actual number of individuals, instead of person-level weights, does not change the results). Conditional on this classification, we obtain the fraction of men and women employed in the linear and in the non-linear occupation. We then compute log mean hours, log mean wages, the standard deviation of $\log$ hours, and the standard deviation of log wages for men and women in each occupation, using person-level weights in the analysis. Finally, for each of the two sectors, we report the averages of these moments, using the relative share of men or women of each occupation in that sector.

Lifetime corrections for the moments. The moments computed from the IPUMS-CPS files are cross-sectional. We use the longitudinal aspect of the Panel Study of Income Dynamics (PSID) to analyze the extent to which the lifetime mean and dispersion in hours and wages differ from the observed cross-sectional mean and dispersion. We impose the following restriction on the PSID: (i) time period 1985-1996, (ii) age 22-64, (iii) married individuals, (iv) positive hours worked, and (v) individuals with positive hours worked in at least five years during that period. First, we compute the mean of hours worked and the standard deviation of $\log$ hours. Second, for each individual in the sample, we compute the mean of hours worked (and refer to it as lifetime hours), and then report the mean lifetime hours and the standard deviation of log lifetime hours. In terms of mean hours, the cross-sectional and the lifetime means are the same. In terms of the dispersion in hours, however, the dispersion in lifetime hours is systematically around two-thirds of the dispersion in cross-sectional hours. Erosa et al. (2016a) report similar findings. These patterns are robust and broadly hold for (i) men and women, (ii) different age groups, (iii) different education groups, (iv) the linear sector and the nonlinear sector of occupations. As a result, in all of the computed moments, we adjust the dispersion in hours worked by a factor of two-thirds.

We repeat the same analysis for hourly wages, instead of hours worked and find that the dispersion in lifetime hourly wages is around $10 \%$ lower than the dispersion in cross-sectional hourly wages. As a result, in all of the computed moments, we adjust the dispersion in hourly wages by a factor of nine-tenths.

Correlations in log hours and log wages between spouses. We use the Panel Study of Income Dynamics (PSID) with the following restrictions: (i) time period 1986-1995, (ii) age 22-64, and (iii) married individuals. We match married spouses and impose the restriction that we have observations on hours and wages for at least three years for both spouses. We then compute average hours and wages for each spouse over the number of years that they are in the restricted sample, and report the resulting correlations in $\log$ hours and $\log$ wages for spouses. Increasing the minimum number of years that both spouses have to be in the sample increases only slightly both correlations - the correlation in log wages (log hours) is $0.43(0.02)$ with a requirement of minimum of three years in the sample, $0.44(0.03)$ with a requirement of minimum of six years in the sample, and $0.44(0.05)$ with a requirement of minimum of nine years in the sample. 


\section{B Intensive and Extensive Margin}

Weeks worked and usual weekly hours: 1986-1995. We see a similar underlying relationship if we look at the patterns in terms of usual hours per week and weeks worked.

Figure B-1: The Log of Mean Weeks vs. the Standard Deviation of Log Weeks, CPS, Men, 1986-1995, by 3-Digit Occupations.

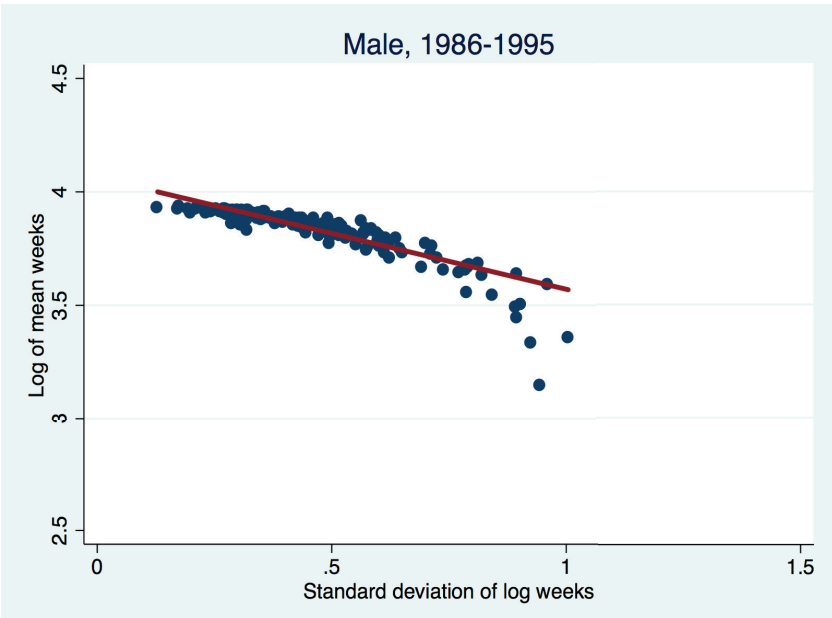

Notes: Each point represents a 3-digit occupation in the 1986-1995 time period.

Figure B-1 shows the relationship between log mean weeks and the standard deviation of log weeks in an occupation. The variable used here is number of week worked last year. Similarly to what we observed for total annual hours worked, there is a negative relationship between the mean number of weeks and the dispersion in weeks worked in a given occupation.

Figure B-2: The Log of Mean Weekly Hours vs. the Standard Deviation of Log Weekly Hours (Usual Hours per Week Last Year), CPS, Men, 1986-1995, by 3-Digit Occupations.

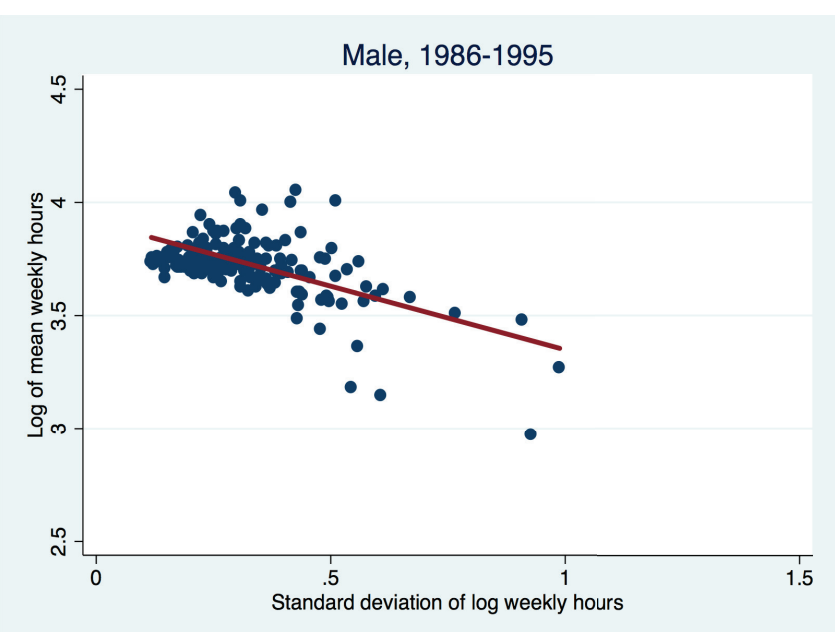

Notes: Each point represents a 3-digit occupation in the 1986-1995 time period. 
Figure B-2 shows the relationship between log mean weekly hours and the standard deviation of log weekly hours in an occupation. The variable used here is usual hours per week last year. Similarly to what we observed for total annual hours worked, there is a negative relationship between the mean hours per week and the dispersion in hours per week in a given occupation.

Figure B-3: The Standard Deviation of Log Weekly Hours vs. the Standard Deviation of Log Weeks, CPS, Men, 1986-1995, by 3-Digit Occupations.

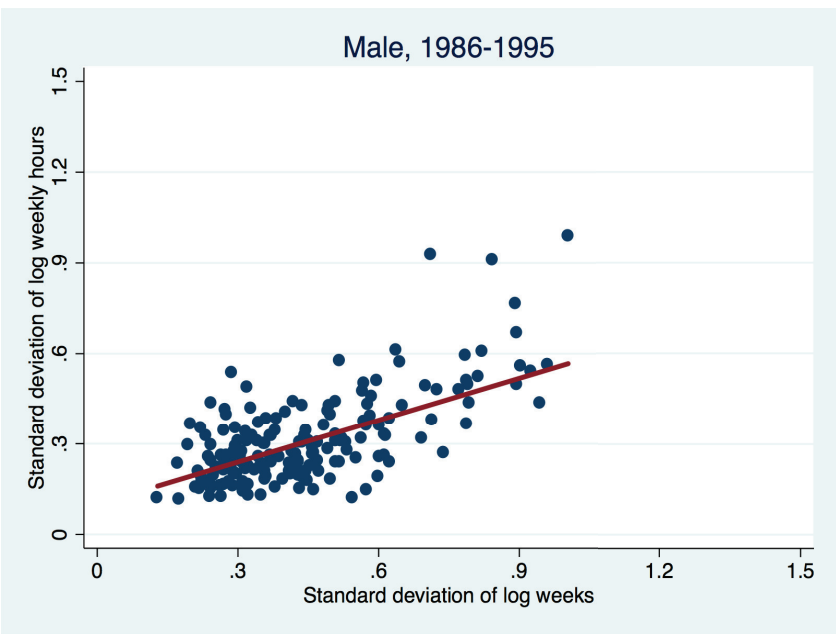

Notes: Each point represents a 3-digit occupation in the 1986-1995 time period.

Finally, we analyze the correlation between weeks worked and weekly hours in occupational hours. Is it the case that occupations that have a high mean and low dispersion in number of weeks worked also exhibit a high mean and low dispersion in usual hours worked in a week? Or is it the other way around? Figure B-3 shows that the correlation between the dispersion in log weekly hours and the dispersion in log weeks in an occupation is positive. This implies that, taking into account the facts described above, some occupations exhibit a high mean and low dispersion in their hours both in terms of usual weekly hours and weeks worked while other occupations exhibit a low mean and high dispersion in their hours both in terms of usual weekly hours and weeks worked. 


\section{Discussion on the value of $\theta$}

In this appendix we present various (and somewhat disparate) pieces of information that relate to our choice of $\theta$ and serve to motivate our choice of $\theta=0.6$ as the value for our benchmark exercises. As noted in the text, our value of $\theta$ is meant to capture both the static and dynamic effects of working longer hours on wages, and we will present information related to both of these components. Also, recall that in our model, $\theta$ denotes the gap between the effect of hours on wages across the two broad groupings of occupations.

\section{Aaronson and French (2004)}

One potential source of information about the value of $\theta$ is the extent of a part-time wage penalty. If $\theta=0$ then the hourly wage rate should not depend on hours worked holding all else constant, whereas if $\theta>0$ then the model would predict a penalty for part time work. Importantly, what is important for us is not the size of the part time wage penalty per se but rather the difference in the size of this penalty across occupations.

There is a large literature that studies the nature of part-time wage penalties. The raw data consistently finds large penalties, often larger than 20\%. A key issue that the literature has recognized is that one needs to control for selection into part-time work-if workers who choose part time work differ from those that choose full time work then the part time wage penalty observed in the raw data may reflect differences in personal characteristics rather than differences in wages holding all else constant. A common finding in the literature is that if one controls for individual characteristics and occupation, then the measured part time penalty is often quite small. Interpreting this for our purposes is complicated, since this finding is quite consistent with the view that the penalty for part time work is small in many occupations and that it is precisely in these occupations that one finds individuals choosing to work part time. In fact, the distribution of part time work across occupations is very skewed.

A key paper for our purposes is Aaronson and French (2004). They exploit the sharp decline in hours worked for working men at the ages of 62 and 65 in US data. They treat this decline in hours worked for those who work (relative to a quadratic age polynomial in hours worked over the life cycle) as exogenous variation in hours worked, and thus a useful instrument in the empirical analysis, caused by the US social security rules that discourage individuals at those ages from working long hours. They find that men who cut their work-week from 40 to 20 hours experience a 20-25\% decline in their hourly wage. In order to control for the fact that workers that reduce their working hours might be also changing the type of work they do on the job, either by switching employers or by switching their occupation within the same employer, they further restrict the analysis to workers that remain in the same job and/or same occupation. Finally, since the various datasets used in the analysis are all longitudinal and follow individuals over time, the estimation controls for individual fixed effects and thus for unobserved quality and productivity differences between those that work long and short number of hours. ${ }^{36}$ Taken at face value, this estimate implies a value for $\theta$ of 0.4. We believe this sample of males moving from full-time to part-time work provides important information about the average penalty for part-time work. Importantly, males are much less likely to be employed in occupations that feature a large share of part time employment. Coupled with the observation that most part time work takes place in occupations in which there is little penalty for part-time work, we feel that this evidence alone suggests that a value of $\theta=0.4$ would be a reasonable benchmark. To the extent that the selection into part-time work in their sample is biased toward occupations in which the penalty is lower, one might want to consider even higher values. Note that this evidence only pertains to the static component of the effect of hours on wages.

Some earlier work also found evidence for the idea of tied hours-wage offers. Moffitt (1984), using taste shifters, such as children, as instruments in a wage on hours regression, and Keane and Wolpin (2001), using a structural model, also find evidence of tied wage-hours offers.

\footnotetext{
${ }^{36}$ In a related and earlier study, Gustman and Steinmeier (1985) document that individuals that enter partial retirement experience - depending on whether they remain in their main job or not - a 15-23\% drop in their hourly wages. Gustman and Steinmeier (1986) argue that a structural model of retirement with such a feature matches very well the labor supply patterns after the age of 60 .
} 


\section{Cortés and Pan (2017b)}

Building on the earlier work of Goldin (2014), Cortés and Pan (2017b) examine the effect of working longer hours on annual earnings, controlling for weeks worked. In contrast to the Aaronson and French (2004) analysis which effectively focused on the penalty for part time work, this study focuses on the returns to working more than 50 hours per week. They present estimates for a set of 16 occupations. They do this using two different sources of data-the Census and the SIPP. When using the Census data they can only look at the contemporaneous relation between hours and wages, but in the case of the SIPP, they can examine both the contemporaneous relation as well as the relation between current hours and wages three years in the future. In their main set of OLS regressions they focus on male full time workers. They find substantial heterogeneity across occupations, and the returns to working longer hours are highly correlated with the propensity to work longer hours. They find that the contemporaneous effects are highly positively correlated across the two data sets and that the static and dynamic effects are highly positive correlated in the SIPP data. There are many caveats to be noted regarding the interpretation of the OLS estimates. But taken at face value, if we sum the static and dynamic effects from their estimates based on the SIPP and consider the interquartile difference, the gap is roughly 0.8. Importantly, their paper goes on to isolate a plausibly exogenous source of variation in the propensity to work longer hours and argue that it is reasonable to interpret the OLS estimates as reflecting causation.

\section{Bertrand et al. (2010) and Gicheva (2013)}

These two studies both focus on the dynamic returns to working longer hours among high skill occupations. As such, they do not present direct evidence on the gap in $\theta$ across broad occupational groups, but we feel that these estimates are quite relevant for thinking about potential differences. Bertrand et al. (2010) study MBA graduates from the Booth School of Business and how their wages and hours evolve over time. They focus on the effects of time away from employment. Gicheva (2013) studies a somewhat broader sample, which consists of individuals who took the GMAT exam. But differently than Bertrand et al. (2010), she focuses on the effects of working longer weekly hours. Hence, one of these studies is implicitly studying the elasticity of wages with respect to variation along the extensive margin, while the other studies the elasticity of wages with respect to variation along the intensive margin.

The main finding from Gicheva (2013) is that there is no effect of hours on wages below 48 hours per week, but that above 48 hours per week, each additional hour increases hourly wage growth by .0019 percent over the first ten years of work. Using this estimate one can perform a simple calculation and compute the effect of going from 48 to 49 hours per week on the present value of lifetime earnings. Gicheva (2013) does such a calculation, using a discount rate of .90 and a twenty year horizon. For our purposes we feel a forty year horizon is more appropriate, and that a discount rate of .95 is more standard. From this calculation we get that an estimate of $1+\theta$ is given by $\Delta \log E-\Delta \log h$, where $E$ is the present value of earnings and $h$ is weekly hours. Using her estimates, this results in an estimate of $\theta=.78$.

The data in Bertrand et al. (2010) allow one to carry out a similar calculation. There are a variety of effects estimates provided in this paper, and here we focus on one that is representative. A key feature of the data is that controlling for a variety of factors, individual who took time away from work during the first six years post graduation experienced large wage losses. Specifically, they find that the average spell away from work was roughly one year and that the effect of this on wages was to decrease wages by $37 \log$ points six years after graduation. Importantly, this estimate controls for differences in hours worked. It is also of interest to note that the overwhelming majority of the time away from work for women is explained by the presence of children. These numbers suggest the following very simple calculation to gauge the implied value of $\theta$. We consider how the wage rate in the sixth year is affected by accumulated years of experience. This suggests a value of $\theta$ equal to $.37 / \log (6 / 5)=2.03$. This is obviously a somewhat select and small sample, but we think it is informative about the potential magnitude of effects in specific occupations.

\section{Sullivan (2010)}

An additional source of potential information is the literature that estimates the return to occupational tenure and how it varies across occupations. The study by Kambourov and Manovskii (2009b) argued that 
occupational human capital is an important component of human capital, and in particular, was more important than firm specific human capital. But their analysis only estimated the average return to occupational human capital. Several researchers have since sought to assess the extent to which the return to occupational specific human capital varies across occupations. See, for example Zangelidis (2008) and Sullivan (2010). To be sure, there are many issues that one faces in trying to separately identify the component of human capital that is occupational specific, and even more so when allowing the parameters to vary by occupation. But at a more general level, the basic message of these papers is consistent with several papers that present evidence for differential effects of experience across broad occupations, with a common finding being that human capital accumulation is much less important in lower wage occupations. See for example, the paper by Adda et al. (2017). Here we present a calculation based on the estimates in Sullivan (2010), who estimated differential returns to occupational tenure using US data. To illustrate the implications for thinking about the heterogeneity in $\theta$ across occupations we focus on two of the occupations that he studied: professional and clerical. His estimates imply a roughly $4 \%$ return per year of occupational human capital in professional occupations and roughly $1 \%$ in clerical. We now do the following hypothetical calculation. Suppose an individual with a working life of 40 years and a discount rate of .95 as above were to take one year off in year ten in each of these two occupations. Looking at lifetime present value of earnings, what would we compute for a value of theta in each of these two occupations. In each case we assume that the return to occupational tenure is constant over time, that the individual has zero earnings in year 10, but that wages continue to

grow from their year 9 level when the individual returns in year 11. The difference in the implied values of $\theta$ is 0.62 .

\section{Summary}

We have presented a variety of evidence that relates to the value of $\theta$ to be used in our quantitative analysis. We do not claim that the evidence reviewed provides a very definitive value for $\theta$. However, we do feel that the evidence presented suggests that a value of $\theta$ at least as large as 0.6 is reasonable, if not somewhat conservative. But given the lack of definitiveness, in our quantitative analysis we will consider the range of values from $\theta=0.4$ to $\theta=1.0$. The broader message of our analysis is relatively unchanged across this range. 


\section{Alternative Calibration Strategy: Targeting All Male Moments}

Table D-1: Calibration Results: Target all Statistics from Males $\theta=0.6$

\begin{tabular}{lllll}
\hline & & & & \\
& & & & \\
& & & & \\
$\mu_{a_{2}}$ & -0.168 & $E^{N L}$ & 0.61 & 0.61 \\
$\sigma_{a_{1}}^{2}$ & 0.321 & $s d\left(\ln w_{N L}\right)$ & 0.45 & 0.49 \\
$\sigma_{a_{2}}^{2}$ & 0.207 & $s d\left(\ln w_{L}\right)$ & 0.46 & 0.43 \\
& & $s d(\ln w)$ & 0.45 & 0.49 \\
$\mu_{\phi}$ & 0.688 & $\ln \bar{h}_{m}$ & 7.67 & 7.68 \\
& & $\ln \bar{h}_{m, N L}$ & 7.73 & 7.76 \\
& & $\ln \bar{h}_{m, L}$ & 7.57 & 7.54 \\
$\sigma_{\phi}^{2}$ & 0.435 & $s d\left(\ln h_{m}\right)$ & 0.26 & 0.27 \\
& & $s d\left(\ln h_{m, N L}\right)$ & 0.22 & 0.17 \\
& & $s d\left(\ln h_{m, L}\right)$ & 0.32 & 0.32 \\
$\rho_{a_{1}, a_{2}}$ & 0.275 & $\ln w_{N L}-\ln w_{L}$ & 0.37 & 0.36 \\
$\rho_{a_{m}, a_{f}}$ & 0.650 & gender corre. log wages & 0.43 & 0.43 \\
$\rho_{\phi_{m}, \phi_{f}}$ & 0.734 & gender corre. log hours & 0.02 & 0.02 \\
$\mu_{a_{m}}-\mu_{a_{f}}$ & 0.327 & gender wage gap & 0.42 & 0.42 \\
$\alpha_{f}$ & 0.789 & $\ln \bar{h}_{f}$ & 7.40 & 7.40 \\
\hline & & & \\
\hline
\end{tabular}


Table D-2: Alternative Calibration: Baseline Economy vs Alternative Economy

Part 1: Data

Males

Emp. share Log mean hours Std log hours Log mean wages Std log wages

\begin{tabular}{llllll}
\hline Non-Linear & 0.61 & 7.73 & 0.22 & 2.56 & 0.45 \\
Linear & 0.39 & 7.57 & 0.32 & 2.19 & 0.46 \\
Aggregate & 1.00 & 7.67 & 0.26 & 2.46 & 0.45 \\
\hline
\end{tabular}

Females

\begin{tabular}{lccccc} 
& Emp. share & Log mean hours & Std log hours & Log mean wages & Std log wages \\
\hline Non-Linear & 0.37 & 7.49 & 0.39 & 2.21 & 0.49 \\
Linear & 0.63 & 7.33 & 0.50 & 1.86 & 0.47 \\
Aggregate & 1.00 & 7.40 & 0.46 & 2.04 & 0.48 \\
\hline
\end{tabular}

Part 2: Baseline

Males

Emp. share Log mean hours Std log hours Log mean wages Std log wages

\begin{tabular}{llllll} 
Non-Linear & 0.60 & 7.75 & 0.16 & 2.56 & 0.48 \\
Linear & 0.40 & 7.52 & 0.31 & 2.22 & 0.43 \\
Aggregate & 1.00 & 7.67 & 0.27 & 2.46 & 0.49 \\
\hline
\end{tabular}

Females

\begin{tabular}{lccccc} 
& Emp. share & Log mean hours & Std log hours & Log mean wages & Std log wages \\
\hline Non-Linear & 0.46 & 7.57 & 0.20 & 2.23 & 0.47 \\
Linear & 0.54 & 7.22 & 0.57 & 1.85 & 0.43 \\
Aggregate & 1.00 & 7.40 & 0.49 & 2.04 & 0.48 \\
\hline
\end{tabular}

Part 3: targeting all statistics of males

Males

Emp. share Log mean hours Std log hours Log mean wages Std log wages

\begin{tabular}{llllll}
\hline Non-Linear & 0.61 & 7.76 & 0.17 & 2.58 & 0.49 \\
Linear & 0.38 & 7.53 & 0.32 & 2.23 & 0.43 \\
Aggregate & 1.00 & 7.68 & 0.27 & 2.46 & 0.49 \\
\hline
\end{tabular}

Females

Emp. share Log mean hours Std log hours Log mean wages Std log wages

\begin{tabular}{llllll} 
Non-Linear & 0.46 & 7.57 & 0.20 & 2.21 & 0.48 \\
Linear & 0.51 & 7.22 & 0.58 & 1.85 & 0.43 \\
Aggregate & 1.00 & 7.40 & 0.49 & 2.04 & 0.48 \\
\hline
\end{tabular}


Table D-3: Alternative Calibration: Shutting Down Time Endowment Differences.

\begin{tabular}{lrr}
\hline & $\theta=0.6$ & $\begin{array}{r}\theta=0.6 \\
\text { Alt. Calib. }\end{array}$ \\
& & \\
Percentage (or percentage point) change in: & & \\
Wage Gap & -11.5 & -11.2 \\
Log Hours Males & -5.3 & -5 \\
Log Hours Females & 27.7 & 27.6 \\
Hours Gap & -33 & -32.3 \\
Std Hours Males & 7.2 & 7 \\
Std Hours Females & -17.3 & -15.2 \\
Share Emp. NL Males & -3.2 & -3 \\
Share Emp. NL Females & 14.1 & 11.5 \\
Log Wage Males & -1.9 & -1.8 \\
Log Wage Females & 9.6 & 9.4 \\
\hline Non-Linear Occupation & & \\
Log Wages Males & -0.4 & -0.6 \\
Log Wages Females & 5 & 5.6 \\
Wage Gap & -5.4 & -6.2 \\
Log Hours Males & -3.5 & -3 \\
Log Hours Females & 20 & 19.7 \\
Hours Gap & -23.5 & -22.7 \\
\hline Linear Occupation & & \\
Log Wages Males & -1.5 & -1.5 \\
Log Wages Females & 3.8 & 3.6 \\
Wage Gap & -5.3 & -5.1 \\
Log Hours Males & -6.3 & -7 \\
Log Hours Females & 29.6 & 29.4 \\
Hours Gap & -35.9 & -36.4 \\
\hline
\end{tabular}

Table D-4: Alternative Calibration: Misallocation.

\begin{tabular}{lrr}
\hline & $\theta=0.6 \quad \begin{array}{r}\theta=0.6 \\
\text { Alt. Calib. }\end{array}$ \\
\hline Percentage change of: & & \\
Aggregate Welfare (cc) & 6.9 & 6.5 \\
Aggregate Output & 1.7 & 1.8 \\
Aggregate Output per Hour & 5.4 & 5.2 \\
\hline
\end{tabular}




\section{E Economy with Gender Differences Only in the Time Endowment}

Assigning parameter values. We assign values for $T_{m}, \gamma$ and $\theta$ based on outside sources. Interpreting a period to be a year, the value of $T_{m}$ is set to 5000, implying a little less than 100 hours of discretionary time per week. We set $\gamma=4$, so that the intertemporal elasticity of leisure along the intensive margin is fixed at a value of $1 / 4$. The value of $\theta$ is clearly a key parameter in our exercise, and as discussed in Section 3, we set this value to 0.6 in our benchmark exercise. It remains to assign the parameters for the discretionary time endowment of women, the population distribution of the idiosyncratic productivity and preference parameters, as well as the correlation of these parameters among spouses.

We adopt the following distributional assumptions. First, and without loss of generality, the mean value of log-ability in occupation 1 is normalized to zero. Second, we impose that the underlying distribution of the $a_{j}$ 's and $\phi$ do not vary across males and females. Women are thus exactly the same as men, except that they have a lower time endowment.

At this point we impose the following additional distributional assumptions:

1. The variance of ability 1 and ability 2 are assumed to be equal $\left(\sigma_{a_{1}}=\sigma_{a_{2}}=\sigma_{a}\right)$;

2. The distributions of $a_{1}, a_{2}$ and $\phi$ are all independent. $\left(\rho_{a_{1}, a_{2}}=\rho_{a_{1}, \phi}=\rho_{a_{2}, \phi}=0\right)$;

3. The correlation of $a_{1}$ between spouses is the same as that of $a_{2}\left(\rho_{a_{1 m}, a_{1 f}}=\rho_{a_{2 m}, a_{2 f}}\right)$.

These assumptions leave us with the following 7 parameters that need to be assigned:

1. Mean value of $\log$ ability in occupation $2\left(\mu_{a_{2}}\right)$;

2. Mean value of log taste for leisure $\left(\mu_{\phi}\right)$;

3. Variance of $\log$ ability in each occupation $\left(\sigma_{a}^{2}\right)$ (which is assumed equal across occupations);

4. Variance of $\log$ taste for leisure $\left(\sigma_{\phi}^{2}\right)$;

5. Correlation of abilities among males and females within couples $\left(\rho_{a_{1 m}, a_{1 f}}\right.$ and $\rho_{a_{2 m}, a_{2 f}}$ which are assumed equal);

6. Correlation between taste for leisure of males and females within couples $\left(\rho_{\phi_{m}, \phi_{f}}\right)$;

7. Time endowment of females $\left(T_{f}\right)$.

Although the endogenous equilibrium outcomes of interest will be jointly determined by all of these parameters, one of the benefits of reducing the set of parameters to these seven is that each of these parameters can intuitively be closely connected with a particular moment of interest. Here we list these connections in turn. The mean value of $\log$ ability in occupation $2\left(\mu_{a_{2}}\right)$ will be closely connected with the share of employment in occupation 2 . The mean value of the log taste for leisure $\left(\mu_{\phi}\right)$ will be closely connected with the mean level of hours worked. The variance of idiosyncratic productivities $\left(\sigma_{a}^{2}\right)$ will be closely connected with the variance of wages. The variance of $\log$ taste for leisure $\left(\sigma_{\phi}^{2}\right)$ will be closely connected with the variance in hours of work. The two correlation parameters linking idiosyncratic values for spouses $\left(\rho_{a_{1 m}, a_{1 f}}=\rho_{a_{2 m}, a_{2 f}}\right.$ and $\rho_{\phi_{m}, \phi_{f}}$ ) will be closely connected to the correlations of hours and wages between spouses. And the time endowment of females $\left(T_{f}\right)$ will be closely connected with the average level of hours worked by females. With these connections in mind we adopt the following targets in our calibration procedure:

1. The share of male employment in occupation 1: 0.61 .

2. Log mean hours of work by men: 7.67 .

3. The standard deviation of log male wages: 0.45 .

4. The standard deviation of log male hours: 0.26 . 
5. The correlation of log wages within households: 0.43 .

6. The correlation of log hours within households: 0.02 .

7. Log mean hours of work by women: 7.40 .

A few remarks are in order. First, note that moments 1 through 4 in this list only involve values for males. As a practical matter we could have targeted the aggregate moments instead of just the moments for males, and our key results are relatively unaffected. So in this sense the choice is not of first order importance. We chose to target the male moments as a way to minimize the extent to which we were targeting moments for females that are related to the moments whose properties we were most interested in.

The calibration is done by minimizing a loss function that sums the square differences between moments in the model and in the data. Table E-1 reports the calibrated parameters as well as the fit of the calibrated model to the targeted moments.

Table E-1: Calibration.

\begin{tabular}{lclcc}
\hline \hline \multirow{2}{*}{ Parameter } & Value & Target & Data & Model \\
\hline$\mu_{a_{2}}$ & -0.202 & $E_{m}^{N L}$ & 0.61 & 0.61 \\
$\mu_{\phi}$ & 0.354 & $\ln \overline{h_{m}}$ & 7.67 & 7.66 \\
$T_{f}$ & 4619 & $\ln \overline{h_{f}}$ & 7.40 & 7.41 \\
$\sigma_{\phi}^{2}$ & 0.384 & $s d\left(\ln h_{m}\right)$ & 0.26 & 0.25 \\
$\sigma_{a_{2}}^{2}$ & 0.238 & $s d\left(\ln w_{m}\right)$ & 0.45 & 0.43 \\
$\rho_{a_{m}, a_{f}}$ & 0.610 & gender corr. of log wages & 0.43 & 0.42 \\
$\rho_{\phi_{m}, \phi_{f}}$ & 0.718 & gender corr. of log hours & 0.02 & 0.02 \\
\hline \hline
\end{tabular}

The model accounts well for all the targeted moments. The baseline model economy accounts for the gender differences in hours of work in the data. Females work less hours than men because they have a time endowment that is about $8 \%$ lower than the one of males (4619 versus 5000 annual hours). The standard deviation of male log wages in the baseline economy is 0.43 , which compares well with the 0.45 value in the data. The standard deviation of male log hours in the baseline economy is 0.25 , which compares well with the 0.26 value in the data.

To account for the high variation in hours of work in the data, the calibration requires substantial heterogeneity in the taste for leisure: $\sigma_{\phi}^{2}=0.384$. The correlation of skills across spouses in the baseline economy is 0.61 , which allows the model to be consistent with the fact that the hourly log wage rate is positively correlated across spouses in the data (0.42 in the model and 0.43 in the data). The taste for leisure is also positively correlated across spouses, with a value of 0.718 , which is needed to match the correlation of hours of work across spouses (0.02 in the data and in the model). The theory can replicate reasonably well the fact that men are more likely to be employed in the non-linear occupation than women.

Results. Table E-2 shows the results. Overall, the baseline economy does a very good job of accounting for the qualitative patterns in the data. Specifically, in terms of aggregate predictions for women relative to men, it predicts that women are disproportionately represented in the linear occupation, have a higher standard deviation of hours, lower mean wages, and a very similar standard deviation of wages, all of which are also true in the data. The model also predicts the negative relationship between mean hours and dispersion in hours across occupations for both men and women. Moreover, mean hours for men are higher 
Table E-2: Baseline Economy with Only Gender Differences in the Time Endowment.

Part 1: Data

Males

Emp. share Log mean hours Std log hours Log mean wages Std log wages

\begin{tabular}{llllll}
\hline Non-Linear & 0.61 & 7.73 & 0.22 & 2.56 & 0.45 \\
Linear & 0.39 & 7.57 & 0.32 & 2.19 & 0.46 \\
Aggregate & 1.00 & 7.67 & 0.26 & 2.46 & 0.45 \\
\hline
\end{tabular}

Females

\begin{tabular}{lccccc} 
& Emp. share & Log mean hours & Std log hours & Log mean wages & Std log wages \\
\hline Non-Linear & 0.37 & 7.49 & 0.39 & 2.21 & 0.49 \\
Linear & 0.63 & 7.33 & 0.50 & 1.86 & 0.47 \\
Aggregate & 1.00 & 7.40 & 0.46 & 2.04 & 0.48 \\
\hline
\end{tabular}

Part 2: Baseline

Males

\begin{tabular}{lccccc} 
& Emp. share & Log mean hours & Std log hours & Log mean wages & Std log wages \\
\hline Non-Linear & 0.61 & 7.74 & 0.16 & 2.53 & 0.41 \\
Linear & 0.39 & 7.53 & 0.29 & 2.34 & 0.43 \\
Aggregate & 1.00 & 7.66 & 0.25 & 2.46 & 0.43 \\
\hline
\end{tabular}

Females

Emp. share Log mean hours Std log hours Log mean wages Std log wages

\begin{tabular}{llllll}
\hline Non-Linear & 0.51 & 7.55 & 0.20 & 2.46 & 0.42 \\
Linear & 0.49 & 7.25 & 0.49 & 2.29 & 0.42 \\
Aggregate & 1.00 & 7.41 & 0.41 & 2.38 & 0.43 \\
\hline \hline
\end{tabular}

in each occupation than are mean hours for women, and the standard deviation of hours for women is higher in each occupation than it is for men. All of these features are also found in the data. Finally, mean wages are lower for women in both occupations, and the standard deviation of wages is similar across both gender and occupation.

The model also does a reasonable job of accounting for the quantitative differences found in the data along some dimensions. For example, in the data, the difference between the fractions of men and women working in the nonlinear occupation is 24 percentage points, this difference in the model is 10 percentage points. Therefore, the model accounts for about $42 \%$ of the observed gender differences in occupational sorting. The model is also quantitatively consistent with the level of mean hours worked for men and women in the nonlinear and linear occupations.

Of particular interest to us is the model's implications for the gender wage gap. As seen in Table E-2, the baseline economy generates a gender wage gap of about $8.2 \%$. The corresponding value in the data is $42 \%$. Thus, the baseline model economy accounts for about $20 \%$ of the "raw" gender wage gap in the data. 
The only difference between males and females in our baseline economy is differences in discretionary time endowments since we assume that the skill distributions are identical. We believe that a gender gap of $8.2 \%$ due purely to differences in discretionary time is very substantial. 


\section{F Sensitivity with Respect to $\theta$}

Table F-1: Sensitivity Analysis: $\theta=1$

Part 1: Data

Males

\begin{tabular}{lccccc} 
& Emp. share & Log mean hours & Std log hours & Log mean wages & Std log wages \\
\hline Non-Linear & 0.61 & 7.73 & 0.22 & 2.56 & 0.45 \\
Linear & 0.39 & 7.57 & 0.32 & 2.19 & 0.46 \\
Aggregate & 1.00 & 7.67 & 0.26 & 2.46 & 0.45 \\
\hline
\end{tabular}

Females

Emp. share Log mean hours Std log hours Log mean wages $\quad$ Std log wages

\begin{tabular}{llllll}
\hline Non-Linear & 0.37 & 7.49 & 0.39 & 2.21 & 0.49 \\
Linear & 0.63 & 7.33 & 0.50 & 1.86 & 0.47 \\
Aggregate & 1.00 & 7.40 & 0.46 & 2.04 & 0.48 \\
\hline
\end{tabular}

Part 2: Economy $\theta=1$

Males

Emp. share Log mean hours Std log hours Log mean wages Std log wages

\begin{tabular}{llllll} 
Non-Linear & 0.62 & 7.77 & 0.12 & 2.58 & 0.47 \\
Linear & 0.38 & 7.46 & 0.29 & 2.22 & 0.45 \\
Aggregate & 1.00 & 7.67 & 0.27 & 2.46 & 0.49 \\
\hline
\end{tabular}

Females

Emp. share Log mean hours Std log hours Log mean wages Std log wages

\begin{tabular}{llllll} 
Non-Linear & 0.41 & 7.63 & 0.13 & 2.25 & 0.45 \\
Linear & 0.57 & 7.20 & 0.54 & 1.85 & 0.45 \\
Aggregate & 1.00 & 7.40 & 0.49 & 2.04 & 0.49 \\
\hline
\end{tabular}


Table F-2: Sensitivity with Respect to $\theta$

Part 3: $\theta=0.4$

Males

Emp. share Log mean hours Std log hours Log mean wages Std log wages

\begin{tabular}{llllll}
\hline Non-Linear & 0.61 & 7.73 & 0.19 & 2.59 & 0.49 \\
Linear & 0.39 & 7.56 & 0.31 & 2.23 & 0.42 \\
Aggregate & 1.00 & 7.67 & 0.26 & 2.46 & 0.49 \\
\hline
\end{tabular}

Females

\begin{tabular}{lccccc} 
& Emp. share & Log mean hours & Std log hours & Log mean wages & Std log wages \\
\hline Non-Linear & 0.51 & 7.53 & 0.25 & 2.21 & 0.48 \\
Linear & 0.49 & 7.25 & 0.56 & 1.84 & 0.42 \\
Aggregate & 1.00 & 7.40 & 0.47 & 2.04 & 0.48 \\
\hline
\end{tabular}

Part 4: Baseline, $\theta=0.6$

\begin{tabular}{|c|c|c|c|c|c|}
\hline \multicolumn{6}{|c|}{ Males } \\
\hline & Emp. share & Log mean hours & Std log hours & Log mean wages & Std log wages \\
\hline Non-Linear & 0.60 & 7.75 & 0.16 & 2.56 & 0.48 \\
\hline Linear & 0.40 & 7.52 & 0.31 & 2.22 & 0.43 \\
\hline Aggregate & 1.00 & 7.67 & 0.27 & 2.46 & 0.49 \\
\hline \multicolumn{6}{|c|}{ Females } \\
\hline & Emp. share & Log mean hours & Std log hours & Log mean wages & Std log wages \\
\hline Non-Linear & 0.46 & 7.57 & 0.20 & 2.23 & 0.47 \\
\hline Linear & 0.54 & 7.22 & 0.57 & 1.85 & 0.43 \\
\hline Aggregate & 1.00 & 7.40 & 0.49 & 2.04 & 0.48 \\
\hline
\end{tabular}

Part 5: $\theta=0.8$

Males

Emp. share Log mean hours Std log hours Log mean wages Std log wages

\begin{tabular}{llllll}
\hline Non-Linear & 0.61 & 7.77 & 0.14 & 2.59 & 0.48 \\
Linear & 0.39 & 7.49 & 0.30 & 2.22 & 0.44 \\
Aggregate & 1.00 & 7.67 & 0.26 & 2.46 & 0.49 \\
\hline
\end{tabular}

Females

Emp. share Log mean hours Std log hours Log mean wages Std log wages

\begin{tabular}{llllll} 
Non-Linear & 0.44 & 7.60 & 0.16 & 2.24 & 0.46 \\
Linear & 0.56 & 7.20 & 0.56 & 1.85 & 0.44 \\
Aggregate & 1.00 & 7.40 & 0.50 & 2.04 & 0.49 \\
\hline
\end{tabular}




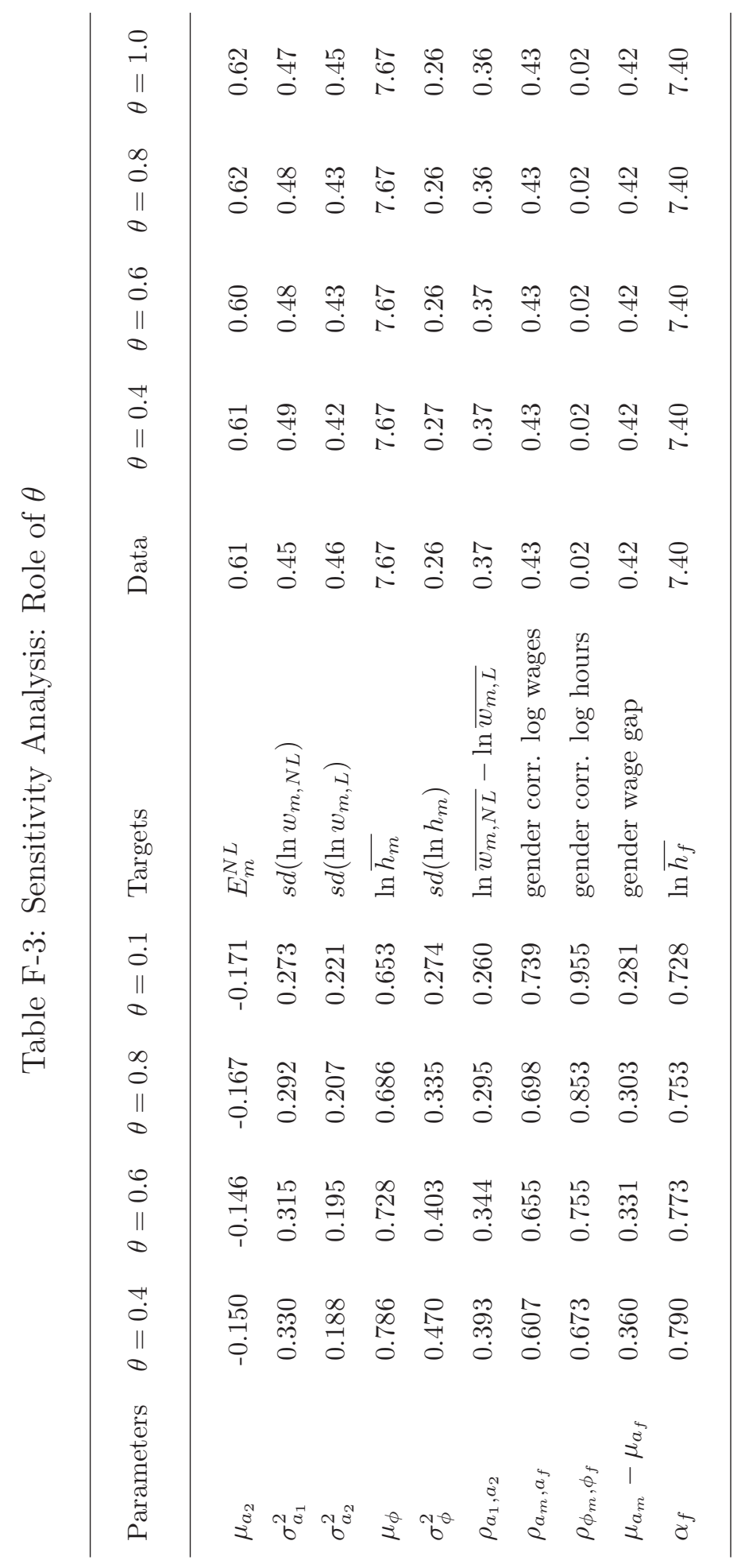




\section{G Consistent 1976-2010 Occupational Classification}

We use the following consistent Occupational Classification system for the analysis from the IPUMS-CPS.

004. Chief executives, public administrators, and legislators

007. Financial managers

008. Human resources and labor relations managers

013. Managers and specialists in marketing, advert., PR

014. Managers in education and related fields

015. Managers of medicine and health occupations

018. Managers of properties and real estate

019. Funeral directors

022. Managers and administrators, n.e.c.

023. Accountants and auditors

024. Insurance underwriters

025. Other financial specialists

026. Management analysts

027. Personnel, HR, training, and labor rel. specialists

028. Purchasing agents and buyers of farm products

029. Buyers, wholesale and retail trade

033. Purchasing managers, agents, and buyers, n.e.c.

034. Business and promotion agents

035. Construction inspectors

036. Inspectors and compliance officers, outside

037. Management support occupations

043. Architects

044. Aerospace engineers

045. Metallurgical and materials engineers

047. Petroleum, mining, and geological engineers

048. Chemical engineers

053. Civil engineers

055. Electrical engineers

056. Industrial engineers

057. Mechanical engineers

059. Engineers and other professionals, n.e.c.

064. Computer systems analysts and computer scientists

065. Operations and systems researchers and analysts

066. Actuaries

068. Mathematicians and statisticians

069. Physicists and astronomists

073. Chemists

074. Atmospheric and space scientists

075. Geologists

076. Physical scientists, n.e.c.
077. Agricultural and food scientists

078. Biological scientists

079. Foresters and conservation scientists

083. Medical scientists

084. Physicians

085. Dentists

086. Veterinarians

087. Optometrists

088. Podiatrists

089. Other health and therapy occupations

095. Registered nurses

096. Pharmacists

097. Dieticians and nutritionists

098. Respiratory therapists

099. Occupational therapists

103. Physical therapists

104. Speech therapists

105. Therapists, n.e.c.

106. Physicians' assistants

154. Subject instructors, college

155. Kindergarten and earlier school teachers

156. Primary school teachers

157. Secondary school teachers

158. Special education teachers

159. Teachers, n.e.c.

163. Vocational and educational counsellors

164. Librarians

165. Archivists and curators

166. Economists, market and survey researchers

167. Psychologists

169. Social scientists and sociologists, n.e.c.

173. Urban and regional planners

174. Social workers

176. Clergy and religious workers

177. Welfare service workers

178. Lawyers and judges

183. Writers and authors

184. Technical writers

185. Designers

186. Musicians and composers

187. Actors, directors, and producers 
188. Painters, sculptors, craft-artists, and print-makers

189. Photographers

193. Dancers

194. Art/entertainment performers and related occs

195. Editors and reporters

198. Announcers

199. Athletes, sports instructors, and officials

203. Clinical laboratory technologies and technicians

204. Dental hygienists

205. Health record technologists and technicians

206. Radiologic technologists and technicians

207. Licensed practical nurses

208. Health technologists and technicians, n.e.c.

214. Engineering technicians

217. Drafters

218. Surveyors, cartographers, mapping scientists/techs

223. Biological technicians

224. Chemical technicians

225. Other science technicians

226. Airplane pilots and navigators

227. Air traffic controllers

228. Broadcast equipment operators

229. Computer software developers

233. Programmers of numerically controlled machine tools

234. Legal assistants and paralegals

235. Technicians, n.e.c.

243. Sales supervisors and proprietors

253. Insurance sales occupations

254. Real estate sales occupations

255. Financial service sales occupations

256. Advertising and related sales jobs

258. Sales engineers

274. Salespersons, n.e.c.

275. Retail salespersons and sales clerks

276. Cashiers

277. Door-to-door sales, street sales, and news vendors

283. Sales demonstrators, promoters, and models

303. Office supervisors

308. Computer and peripheral equipment operators

313. Secretaries and stenographers

315. Typists

316. Interviewers, enumerators, and surveyors

317. Hotel clerks
318. Transportation ticket and reservation agents

319. Receptionists and other information clerks

326. Correspondence and order clerks

328. Human resources clerks, excl. payroll and timekeeping

329. Library assistants

335. File clerks

336. Records clerks

337. Bookkeepers and accounting and auditing clerks

338. Payroll and timekeeping clerks

344. Billing clerks and related financial records processing

346. Mail and paper handlers

347. Office machine operators, n.e.c.

348. Telephone operators

349. Other telecom operators

354. Postal clerks, excluding mail carriers

355. Mail carriers for postal service

356. Mail clerks, outside of post office

357. Messengers

359. Dispatchers

361. Inspectors, n.e.c.

364. Shipping and receiving clerks

365. Stock and inventory clerks

366. Meter readers

368. Weighers, measurers, and checkers

373. Material recording, sched., prod., plan., expediting cl.

375. Insurance adjusters, examiners, and investigators

376. Customer service reps, invest., adjusters, excl. insur.

377. Eligibility clerks for government prog., social welfare

378. Bill and account collectors

379. General office clerks

383. Bank tellers

384. Proofreaders

385. Data entry keyers

386. Statistical clerks

387. Teacher's aides

389. Administrative support jobs, n.e.c.

405. Housekeepers, maids, butlers, and cleaners

408. Laundry and dry cleaning workers

415. Supervisors of guards

417. Fire fighting, fire prevention, and fire inspection occs

418. Police and detectives, public service

423. Sheriffs, bailiffs, correctional institution officers

425. Crossing guards

426. Guards and police, except public service 
427. Protective service, n.e.c.

433. Supervisors of food preparation and service

434. Bartenders

435. Waiters and waitresses

436. Cooks

439. Food preparation workers

444. Miscellaneous food preparation and service workers

445. Dental Assistants

447. Health and nursing aides

448. Supervisors of cleaning and building service

450. Superv. of landscaping, lawn service, groundskeeping

451. Gardeners and groundskeepers

453. Janitors

455. Pest control occupations

457. Barbers

458. Hairdressers and cosmetologists

459. Recreation facility attendants

461. Guides

462. Ushers

464. Baggage porters, bellhops and concierges

466. Recreation and fitness workers

467. Motion picture projectionists

468. Child care workers

469. Personal service occupations, n.e.c

470. Supervisors of personal service jobs, n.e.c

471. Public transportation attendants and inspectors

472. Animal caretakers, except farm

473. Farmers (owners and tenants)

475. Farm managers

479. Farm workers, incl. nursery farming

488. Graders and sorters of agricultural products

489. Inspectors of agricultural products

496. Timber, logging, and forestry workers

498. Fishers, marine life cultivators, hunters, and kindred

503. Supervisors of mechanics and repairers

505. Automobile mechanics and repairers

507. Bus, truck, and stationary engine mechanics

508. Aircraft mechanics

509. Small engine repairers

514. Auto body repairers

516. Heavy equipment and farm equipment mechanics

518. Industrial machinery repairers

519. Machinery maintenance occupations
523. Repairers of industrial electrical equipment

525. Repairers of data processing equipment

526. Repairers of household appliances and power tools

527. Telecom and line installers and repairers

533. Repairers of electrical equipment, n.e.c.

534. Heating, air conditioning, and refrigeration mechanics

535. Precision makers, repairers, and smiths

536. Locksmiths and safe repairers

539. Repairers of mechanical controls and valves

543. Elevator installers and repairers

544. Millwrights

549. Mechanics and repairers, n.e.c.

558. Supervisors of construction work

563. Masons, tilers, and carpet installers

567. Carpenters

573. Drywall installers

575. Electricians

577. Electric power installers and repairers

579. Painters, construction and maintenance

583. Paperhangers

584. Plasterers

585. Plumbers, pipe fitters, and steamfitters

588. Concrete and cement workers

589. Glaziers

593. Insulation workers

594. Paving, surfacing, and tamping equipment operators

595. Roofers and slaters

597. Structural metal workers

598. Drillers of earth

599. Misc. construction and related occupations

614. Drillers of oil wells

615. Explosives workers

616. Miners

617. Other mining occupations

628. Production supervisors or foremen

634. Tool and die makers and die setters

637. Machinists

643. Boilermakers

644. Precision grinders and fitters

645. Patternmakers and model makers

649. Engravers

653. Other metal and plastic workers

657. Cabinetmakers and bench carpeters

658. Furniture/wood finishers, other prec. wood workers 
666. Dressmakers, seamstresses, and tailors

668. Upholsterers

669. Shoemakers, other prec. apparel and fabric workers

675. Hand molders and shapers, except jewellers

677. Optical goods workers

678. Dental laboratory and medical appliance technicians

679. Bookbinders

684. Other precision and craft workers

686. Butchers and meat cutters

687. Bakers

688. Batch food makers

694. Water and sewage treatment plant operators

695. Power plant operators

696. Plant and system operators, stationary engineers

699. Other plant and system operators

703. Lathe, milling, and turning machine operatives

706. Punching and stamping press operatives

707. Rollers, roll hands, and finishers of metal

708. Drilling and boring machine operators

709. Grinding, abrading, buffing, and polishing workers

713. Forge and hammer operators

719. Molders and casting machine operators

723. Metal platers

724. Heat treating equipment operators

727. Sawing machine operators and sawyers

729. Nail, tacking, shaping and joining mach ops (wood)

733. Other woodworking machine operators

734. Printing machine operators, n.e.c.

736. Typesetters and compositors

738. Winding and twisting textile and apparel operatives

739. Knitters, loopers, and toppers textile operatives

743. Textile cutting and dyeing machine operators

744. Textile sewing machine operators

745. Shoemaking machine operators

747. Clothing pressing machine operators

749. Miscellaneous textile machine operators

753. Cementing and gluing machine operators

754. Packers, fillers, and wrappers

755. Extruding and forming machine operators
756. Mixing and blending machine operators

757. Separating, filtering, and clarifying machine operators

763. Food roasting and baking machine operators

764. Washing, cleaning, and pickling machine operators

765. Paper folding machine operators

766. Furnace, kiln, and oven operators, apart from food

769. Slicing, cutting, crushing and grinding machine

774. Photographic process workers

779. Machine operators, n.e.c.

783. Welders, solderers, and metal cutters

785. Assemblers of electrical equipment

789. Painting and decoration occupations

799. Production checkers, graders, and sorters in manufacturing

803. Supervisors of motor vehicle transportation

804. Truck, delivery, and tractor drivers

808. Bus drivers

809. Taxi cab drivers and chauffeurs

813. Parking lot attendants

823. Railroad conductors and yardmasters

824. Locomotive operators: engineers and firemen

825. Railroad brake, coupler, and switch operators

829. Ship crews and marine engineers

834. Miscellaneous transportation occupations

844. Operating engineers of construction equipment

848. Crane, derrick, winch, hoist, longshore operators

853. Excavating and loading machine operators

859. Stevedores and misc. material moving occupations

865. Helpers, constructions

866. Helpers, surveyors

869. Construction laborers

873. Production helpers

875. Garbage and recyclable material collectors

878. Machine feeders and offbearers

885. Garage and service station related occupations

887. Vehicle washers and equipment cleaners

888. Packers and packagers by hand

889. Laborers, freight, stock, and material handlers, n.e.c. 